Florida International University FIU Digital Commons

$11-3-2004$

\title{
The therapeutic effects of Millon Clinical Multiaxial Inventory-III assessment feedback
}

Andrea Allen

Florida International University

Andrea Allen Keener

DOI: $10.25148 /$ etd.FI13101584

Follow this and additional works at: https://digitalcommons.fiu.edu/etd

Part of the Psychology Commons

\section{Recommended Citation}

Allen, Andrea and Keener, Andrea Allen, "The therapeutic effects of Millon Clinical Multiaxial Inventory-III assessment feedback" (2004). FIU Electronic Theses and Dissertations. 1225.

https://digitalcommons.fiu.edu/etd/1225

This work is brought to you for free and open access by the University Graduate School at FIU Digital Commons. It has been accepted for inclusion in FIU Electronic Theses and Dissertations by an authorized administrator of FIU Digital Commons. For more information, please contact dcc@fiu.edu. 


\section{FLORIDA INTERNATIONAL UNIVERSITY}

Miami, Florida

THE THERAPEUTIC EFFECTS OF MILLON CLINICAL MULTIAXIAL

INVENTORY-III ASSESSMENT FEEDBACK

A dissertation submitted in partial fulfillment of the

requirements for the degree of

DOCTOR OF PHILOSOPHY

in

PSYCHOLOGY

by

Andrea Allen

2004 
To: Dean R. Bruce Dunlap

College of Arts and Sciences

This dissertation, written by Andrea Allen, and entitled The Therapeutic Effects of Millon Clinical Multiaxial Inventory-III Assessment Feedback, having been approved in respect to style and intellectual content, is referred to you for judgment.

We have read this dissertation and recommend that it be approved.

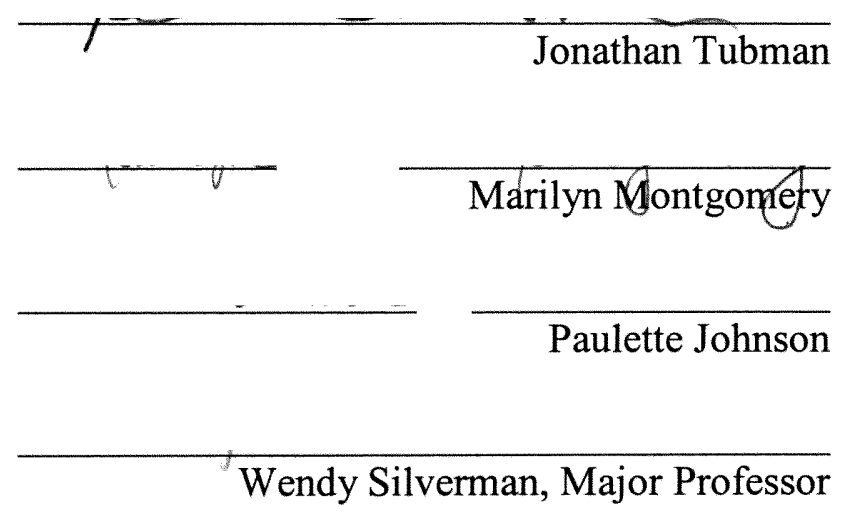

Date of Defense: November 3, 2004

The dissertation of Andrea Allen is approved.

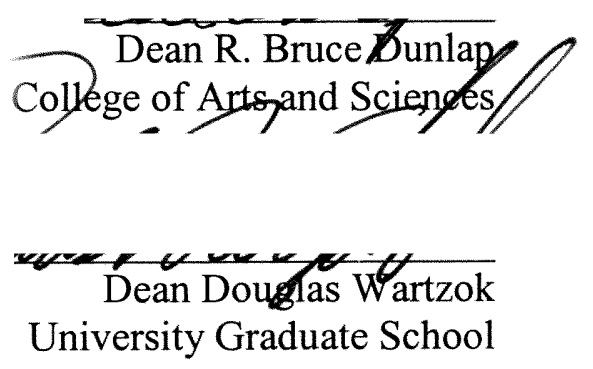

Florida International University, 2004 


\section{DEDICATION}

To my husband, Larry, and my children, Tommy, Laura, and David. Your love and support provide me with a mechanism for being. 


\section{ACKNOWLEDGMENTS}

I would like to thank the members of my committee for guiding me through this dissertation. Dr. Jonathan Tubman and Dr. Marilyn Montgomery have provided me with encouragement for this project from its inception and have given immeasurable support throughout. Dr. Paulette Johnson's clear and concise methodological advice has been most appreciated. I am indebted to my Major Professor, Wendy Silverman, for helping me strive towards excellence academically, professionally, and personally. Finally, I would like to thank Dr. Luis Escovar without whom this dissertation would never have been possible. His teachings have provided me with the conceptual framework for this project; his kindness, compassion, and therapeutic skill continue to inspire me. 
ABSTRACT OF THE DISSERTATION

THE THERAPEUTIC EFFECTS OF MILLON CLINICAL MULTIAXIAL

INVENTORY-III ASSESSMENT FEEDBACK

by

Andrea Allen

Florida International University, 2004

Miami, Florida

Professor Wendy Silverman, Major Professor

A study was conducted to test the therapeutic effects of assessment feedback on rapport-building and self-enhancement variables (self-verification, self-discovery, selfesteem), as well as symptomatology. Assessment feedback was provided in the form of interpretive information based on the results of the Millon Clinical Multiaxial InventoryIII (MCMI-III). Participants $(\mathrm{N}=89)$ were randomly assigned to three groups: a Feedback group, a Reflective-Counseling group, and a No-Feedback group. The Feedback group was provided with assessment feedback, the Reflective-Counseling group was asked to comment on the meaning of the taking the MCMI-III, the NoFeedback group received general information about the MCMI-III. Results revealed that assessment feedback, when provided in the form of interpretive interpretation positively affects rapport-building and self-enhancement variables (self-verification and selfdiscovery). No significant results were found in terms of self-esteem or symptom decrease as a function of feedback. However, a significant decrease in symptoms across groups was found. Results indicate that assessment feedback in the form of interpretive information can be used as a starting point in therapy. Implications of the findings are discussed with respect to theory and clinical practice. 
I. INTRODUCTION.

Feedback as a Therapeutic Tool.

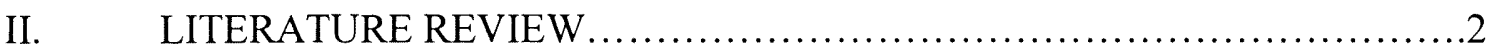

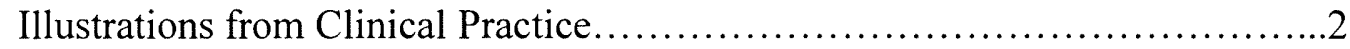

Feedback as a Clinical Modality........................................... 7

Empirical Support for the Benefits of Providing Assessment Feedback..........8

Theoretical Explanations for the Effectiveness of Assessment Feedback........14

The Barnum Effect................................................. 18

Summary of Literature on Assessment Feedback...............................20

The Present Study .......................................................

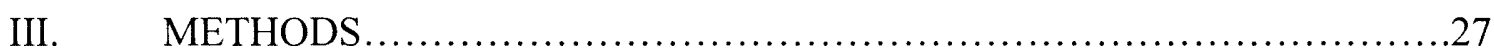

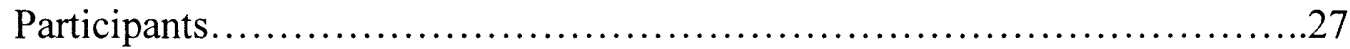

Procedure..............................................................

Measures................................................................

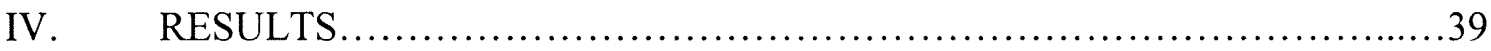

Group Comparability....................................................

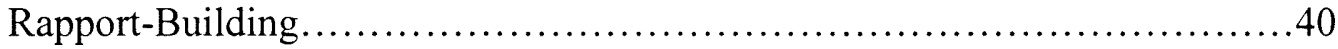

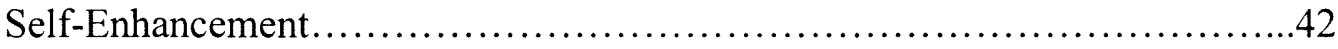

Symptom Decrease................................................43

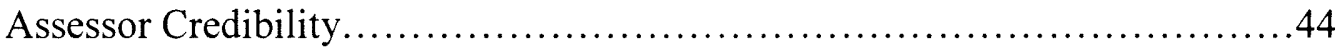

Treatment Integrity ................................................... 44

Assessor Effects...................................................46

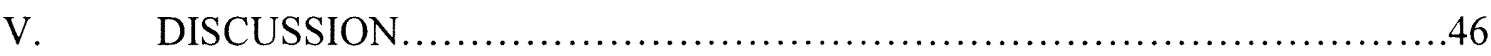

Summary of Findings.................................................46

Participants' Relationship with Assessor..................................48

Participants' Reactions to Assessment...................................49

Effects of Assessment Feedback on Self-Enhancement Processes..............51

Effects of Assessment Feedback on Symptoms.................................53

Theoretical Implications of Findings.....................................5

Assessor Credibility .................................................. 56

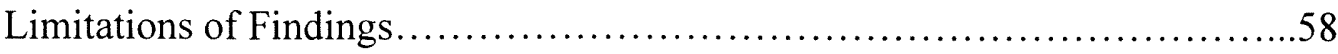

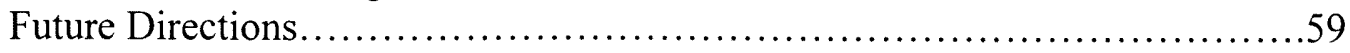

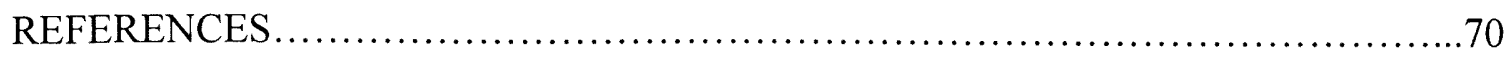

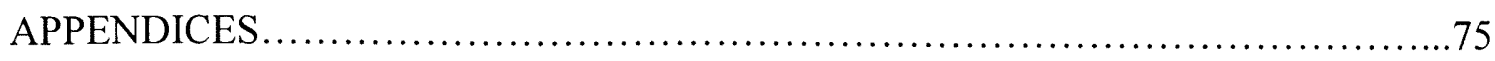

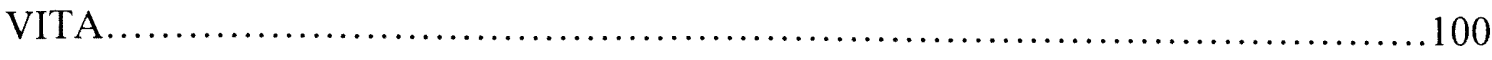


1. Sociodemographic Characteristics of Participants in Feedback, ReflectiveCounseling and No-Feedback Groups.

2. Sociodemographic Characteristics of Participants in Feedback, ReflectiveCounseling and No-Feedback Groups (Age)

3. Means and Standard Deviations on Rapport-Building, Self-Enhancement and Symptomatology Measures by Groups 63

4. Multivariate and Univariate Analyses of Variance for Rapport-Building Measures...64

5. Multivariate and Univariate Analyses of Variance for Self-Enhancement Measures (Self-Verification \& Self-Discovery)

6. Multivariate and Univariate Analyses of Variance for Repeated Self-Enhancement Measures (Self-Esteem) and Symptomatology (BSI)............................66

7. Univariate Analysis of Variance for Repeated Symptomatology Measure (BSI)......67

8. Means and Standard Deviations on Treatment Integrity Variables 68

9. Multivariate and Univariate Analyses of Variance for Assessor Credibility and Treatment Integrity. 


\section{INTRODUCTION}

Feedback as a Therapeutic Tool

The American Psychological Association's current ethical guidelines state that clients should be given feedback about their assessment results (ES: 9.10, American Psychological Association, 2002). Providing feedback to clients about assessment results as a formal approach to therapy, however, has received relatively little attention in the clinical literature. Thus, the effects that assessment feedback can have on the therapeutic process are still largely underinvestigated. Feedback has broadly been described as a therapeutic intervention aimed at enhancing and increasing a client's awareness of his or her thoughts, feelings, and actions (Arkowitz, 1992). It is said to strengthen the doctorpatient relationship while giving the patient rightfully deserved access to testing results (Rozensky, Sweet, \& Tovian, 1997). Baker (1987) emphasized that providing patients with testing results reduces defensiveness about therapy, thereby enhancing clinicians' chances for building rapport and ensuring a more positive treatment outcome. Although not widespread, there is support for the notion that providing feedback about assessment results to clients can be positive and therapy enhancing. However, empirical studies testing its effects are small in number.

Because medical as well as psychological practice is heavily influenced by the existing managed care system, doctors and clinicians find themselves in a position where they are not only asked by their clients to satisfy their justified expectations to find symptom relief, but also by health care administrators to fulfill specific requirements under narrowly set guidelines. To provide clients with quality-oriented and effective 
therapy, new directions have to be taken (Quirk, Strohsahl, Kreilkamp, \& Erdberg, 1995). More recently, a change in the views of the purpose of assessment results has occurred. Increasingly, the therapeutic benefits of providing clients with feedback about their assessment results have been noted (for a review, see Finn, 1996). As the interest in treatment models using assessments as both a diagnostic as well as a therapeutic tool is increasing (Dunn, Deroo, \& Rivera, 2001), so too is the necessity of learning more about the specific effects of assessment feedback.

The following review of the literature shows that feedback has been identified as a treatment enhancing modality by researchers from diverse theoretical persuasions. Ensuing sections discuss how assessment feedback has been used thus far, followed by a discussion of the theoretical explanations for the effects of assessment feedback.

\section{LITERATURE REVIEW}

\section{Illustrations from Clinical Practice}

Assessment feedback as part of the assessment process. Butcher (1990) regards the provision of test feedback as the therapist's duty to the client. He argues that clients rightfully expect direct feedback from an ethical and professional therapist to help facilitate the therapeutic process. Butcher (1990) further outlines a framework for providing MMPI-2 (Butcher, Dahlstrom, Graham, Tellegen, \& Kaemmer, 1989) feedback for clients entering treatment. This framework provides a 7-step procedure for giving clients test feedback in a clinical setting. The first step involves explaining to the client why the MMPI-2 is used as an assessment tool. The second step gives the client general information about the MMPI-2 and explains its broad usage in the clinical field. The third step outlines how the MMPI-2 works by briefly discussing scale development and score interpretation. The fourth step discusses the meaning of the validity scales. Butcher views 
the fourth step as one of the most important parts of the feedback assessment session as it provides an opportunity to discuss the client's approach to the test itself and thus offers a gauge of the client's motivation for treatment.

In step five, the client's profile elevations are elaborated on. The client is provided with feedback about how his or her low or high scores on the MMPI-2 profiles compare with normative data. Attention should be given not only in providing information about profile elevations indicating problematic areas in the client's functioning, but discussing areas where the client appears to function well. This information should be provided in an easily understandable way without the use of psychological jargon. The therapist should focus on the most "pertinent features" (Butcher, 1990, p. 151), while being sensitive to the client's acceptance/non-acceptance of the information in an effort to avoid overwhelming the client. Step six emphasizes client involvement in the feedback session. The therapist should request client input including questions about the test or scores to avoid misunderstanding or misinterpretations.

Butcher (1990) also stresses that fostering an active dialogue can be treatmentenhancing by increasing clients' insights into their problems. Step seven, the final step, involves asking the client to provide a summary of the feedback session. By doing so, the therapist can find out whether parts of the assessment were not accepted by the client, were deemed overly distressing, or both. This step also functions as a transitional step into therapy, by allowing both therapist and client to begin focusing on salient issues that can be addressed therapeutically. Butcher further recommends considering more than one assessment feedback session. During the second session, the client would again be asked 
to summarize the information provided by the therapist, while the therapist has an opportunity to repeat salient points and/or refresh the client's memory.

Although Butcher (1990) clearly points out the necessity, utility, and efficaciousness of providing assessment feedback, his decision to provide such feedback is a pragmatic and ethical one rather than an empirically supported one. As discussed in the following sections, a number of other professionals have developed methodologies for providing feedback to clients.

Assessment feedback as part of a therapy modality. Another practical approach to feedback has been developed by Miller (1995) while working with clients' substance abuse problems. Within the framework of Motivational Enhancement Therapy (MET; Miller \& Rollnick, 1991), Miller believes "feedback to clients on their Substance Abuse Subtle Screening Inventory (SASSI; Miller, 1997) profiles is useful to increase the client's awareness, eliciting further information, and establishing rapport (p.1)." Miller credits the "persuasiveness of personal feedback" (Miller, 1995, p. 92) with the motivational effects it appears to have in a therapeutic setting. Although general information rarely changes drinking behavior, personal information about one's drinking behavior can lead to a change in thinking patterns and ultimately to therapeutic change (Miller, 1995).

Within this motivational framework, Miller adopted the Stages of Change model described by Prochaska and DiClemente (1994) in their transtheoretical approach. According to the Stages of Change model, the process of change can be divided into various stages. These stages are Precontemplation, Contemplation, Determination, Action, Maintenance, and Relapse. In the Precontemplation stage, a client is unaware that there might be a problem, and therefore is not even considering change. People in the 
Precontemplation stage would rarely seek treatment on their own. The Contemplation stage is fraught with feelings of ambivalence. Change is being considered, but no actions are yet taken. The Determination stage marks the point where a decision in favor of change is made. This stage can mark the beginning phase of therapy. The Maintenance stage is crucial in that it marks the period of time when therapeutic gains are solidified and relapse is prevented. Relapse is the oftentimes unavoidable stage where the client may slip and fall back to less therapeutically advantageous habits. This stage is regarded as another step in the change process because it can lead to a permanent maintenance state.

Motivational Interviewing seeks to motivate Precontemplators and Contemplators to willingly engage in a process of change. Miller (1995) made the provision of personal feedback the first step in a 6-step motivational counseling intervention modality, which he refers to as FRAMES. This modality has been used in working with substance users and abusers. The different steps of this intervention are Feedback, Responsibility, Advice, Menu, Empathy, and Self-Efficacy (Miller, 1995). Miller regards feedback as a persuasive and motivational technique, and he uses it as his first therapeutic intervention strategy.

According to Miller (1995), feedback should consist of individual and personal information gathered from an assessment, which may be the client's intake interview, neuropsychological testing, or another data collection modality. Responsibility refers to putting emphasis on the client's ability to choose and the necessity to take responsibility for one's actions. Advice refers to the motivational technique used to outline to the client how change might be accomplished. To emphasize the client's choice, Menu is a technique employed to ensure that rather than offering only one choice to a client, several 
choices are developed. In doing so, the client's active engagement is sought. Rogerian Empathy should be used to increase client motivation. The final technique, Self-Efficacy, refers to increasing motivation by instilling a feeling in the client that change is possible. An optimistic atmosphere is created in the attempt to convey hope and engagement on the part of the therapist.

Empirical support for feedback as part of MET. Motivational Interviewing is an interactive, client-engaging technique aimed at moving a client from a Precontemplating or Contemplating stage to a Determination or Action stage. Although the motivational interviewing style is non-confrontational and empathic, the goal is to develop a sense of discrepancy in the client's appraisal about his or her current situation. Ideally, clients should recognize how their present behaviors interfere with their personal goals or values. Although a recent study found Motivational Interviewing interventions to be effective in engaging clients in therapy (Dunn et al., 2001), the specific causes for this effectiveness have yet to be successfully isolated. Miller's Motivational Interviewing (Miller, \& Rollnick, 1991) has been further tested empirically by Hickman (1997), Aubrey (1998), and DiClemente, Bellino, and Neavins (1999) in their alcoholism research. The U.S. Department's Center for Substance Abuse Treatment (CSAT) published a manual for adolescent cannabis users (Sample \& Kadden, 2001) that incorporates MET and the provision of personalized feedback into a recommended treatment program.

Hickman (1997) investigated whether the provision of individualized feedback leads to a greater reduction in alcohol consumption than treatment without feedback. Hickman (1997) found that providing feedback according to Miller (Miller, Zweben, DiClemente, \& Rychtarik, 1995) in a sample of clients who were "dually diagnosed," 
(e.g., met diagnostic criteria for a DSM-IV Axis I disorder and a substance abuse disorder) led to a reduction in alcohol consumption, as well as to a decrease in psychopathology symptoms. The decreases in symptoms, as assessed by the SCL-90-R, occurred in areas of depression, anxiety and interpersonal functioning. Within Miller's theoretical framework, Hickman hypothesized that feedback enhances a client's motivation for change and subsequently leads to successful treatment outcomes. Because the study did not identify personalized feedback as the actual factor leading to the decrease in symptomatology, Hickman proposed that the reduction in alcohol intake might also contribute to decreased scores on the SCL-90-R. Further studies are needed to isolate the specific therapeutic effects of feedback.

\section{Feedback as a Clinical Modality}

Finn (1996) developed a practical methodology for providing feedback to clients on the results of the MMPI-2. Based largely on Butcher's (1990) model of providing feedback, Finn's approach focuses on helping the client set up questions that he or she would like answered based on the test results. Once the client completes the instrument, the clinician addresses the questions and provides answers based on the test results. The entire process is done within a collaborative approach. Finn calls his approach "therapeutic assessment" (Finn, 1996), and outlines a 5-step procedure for providing feedback to clients.

Within his framework, Finn (1996) recommends an initial 60-90 minute interview with the client. During this interview, the therapist encourages the client to formulate questions the client would like answered with the help of the MMPI-2 while using the time to build rapport. The MMPI-2 is administered as part of step two. 
In step 3, the feedback session is outlined by the therapist. The therapist is encouraged to focus first on providing information to the client that is familiar in nature while moving towards more and more novel information as the session progresses. Step 4 involves the actual feedback session with the client. During this session, the client is asked to discuss any feelings he or she may have about the assessment procedures. Also, the client is reminded of the assessment questions he or she was to prepare. Information gathered from the MMPI-2 assessment is presented to the client in form of a communication. Throughout this process, the client is asked to verify the findings. The assessment questions are answered by referring to MMPI- 2 assessment results. The final step, step 5 , involves the provision of a written report to the client summarizing the feedback session and the information provided therein.

\section{Empirical Support for the Benefits of Providing Assessment Feedback}

The previous sections discussed assessment feedback as a suggested treatment modality that can be used as a therapeutic tool. Although providing feedback to clients is highly recommended (Baucom \& Epstein, 1990; Butcher, 1990; Finn, 1996; Miller, 1995), empirical support for its efficacy as a treatment modality needs to be established. The following section discusses the empirical research studies in the area of assessment feedback.

Assessment feedback using the MMPI-2. Research in the field of personality assessment feedback using the Minnesota Multiphasic Personality Inventory and the Minnesota Multiphasic Personality Inventory 2 (MMPI and MMPI-2; Butcher et al., 1989 ) as testing tools further underlines the positive effects of feedback. Finn and Tonsager (1992) designed a study testing the benefits of disclosing assessment results in the form of feedback to clients using the MMPI-2 (Butcher et al., 1989). Participants 
completed additional measures, including a questionnaire assessing their subjective impressions of a test feedback session. Only participants in the experimental group completed the MMPI-2. Participants in the control group completed the other measures; however, they did not complete the MMPI-2.

The feedback provided to clients was based on their results from the MMPI-2. The 60 participants of the study were recruited from an outpatient college clinic waiting list. The clients, who were predominantly female $(n=42)$, with an average age of 23 years, were assigned to one of two groups. The experimental group $(n=32)$ was asked to complete the MMPI-2 and then received feedback about their test results. The control group $(n=28)$ did not complete the test, but received attention from the experimenter equal in time to that of the experimental group. The experimental group showed a significant decrease in symptomatic distress and increase in self-esteem, and was more hopeful about the future than the control group.

In Newman and Greenway's (1997) subsequent study, both groups of participants completed the MMPI-2, thus correcting an omission of the Finn and Tonsager study. Participants ( $N=60 ; 46$ female, 14 male) were recruited from a university counseling center in Australia. Both groups met with the examiner individually before completing the MMPI-2 to discuss their current problem areas and the nature of the subsequent psychological testing. The experimental group received MMPI-2 test feedback two weeks after taking the test. The control group received supportive attention two weeks after the assessment. During this session, clients of the control group were asked to either clarify or add questions they might want to have answered from the assessment followed by a completion of the outcome measures. Participants of the control group received test feedback two weeks later after having completed the outcome measures. Participants in 
the experimental group reported a significant increase in self-esteem and decrease in symptomatic distress as assessed by the SCL-90-R during the 2-week follow-up when compared to the control group.

Assessment feedback using a Millon inventory. More recently, Allen, Montgomery, Tubman, Frazier, and Escovar (2003) expanded on Finn and Tonsager's (1992) study by further elucidating the effects of assessment feedback on rapportbuilding and self-enhancement processes. The study was conducted using a nonclinical sample of college students. Feedback was provided based on results from the Millon Index of Personality Styles (MIPS; Millon, Weiss, Millon, \& Davis, 1994). Although all participants of the study completed the MIPS, only the experimental group received personalized assessment feedback. The control group received general information about the personality inventory. Results showed that rapport-related variables and selfenhancement variables were significantly higher in the assessment feedback group than the control group. Although Allen et al.'s (2003) study suggests providing feedback about assessment results positively impacts rapport-building and self-enhancement, further research is needed to replicate the findings, particularly in clinical samples.

The studies reviewed provide empirical support for the potential positive effects of assessment feedback. Specifically, these studies' findings show that completing an inventory does not bring about positive therapeutic outcome, but providing feedback does. Overall, the results of these studies help further understanding of the effects of assessment feedback on therapeutic outcomes.

Assessment feedback as part of marital satisfaction assessment--Illustrations from marital and couples therapy. Although research in the field of assessment feedback is limited, it has received some attention from marital therapy researchers. Baucom and 
Epstein (1990) believe that giving feedback to couples regarding assessment has explicitly positive effects. Baucom and Epstein (1990) emphasize the appropriateness of giving feedback to couples about not only their relationship, but also about the therapist's conceptualization of their relationship and proposed treatment thereof. Several reasons for this are pointed out. Not only can feedback help clients view their problems more objectively and therefore more clearly-something that may not always be feasible in times of marital discord without therapeutic intervention - it aids them in understanding their problems. Moreover, feedback could provide the clients with information about the therapist's proposed intervention methods. This may facilitate the establishment of treatment goals. Baucom and Epstein (1990) further stress that the client-therapist relationship may be enhanced and rapport-building increased.

Truitt (1999) developed a methodology to provide feedback to couples on the results of the MCMI-III. Her aim was to develop ways of combining assessment information with domain-oriented conjoint treatment approaches so that the couple will plan strategies for change. Worthington et al. (1995) used feedback techniques as part of a marital satisfaction assessment. These researchers found that individualized relationship assessment and feedback have a positive impact on perceived satisfaction in the relationship. The study involved 48 college students and their respective partners. Couples were assigned to either an assessment feedback condition or to a writtenassessment-only condition. Couples completed several relationship measures together with a client rating form assessing the assessor's competence.

The results showed that the couples' relationships in the assessment feedback group showed more improvement over time than couples in the written-assessment-only condition. The importance of the findings of the study are twofold: The results lend 
support to the theory that assessment feedback has positive effects, and these effects are not restricted to a clinical sample but can be generalized to a non-clinical group of people.

The previous discussion suggests that feedback has positive effects on multiple levels. Not only can feedback help decrease clients' symptoms within a clinical setting, it also increases clients' perceived well-being in a non-clinical setting. Using testing batteries such as personality inventories as part of therapy does not only aid the clinician in arriving at a valid diagnosis, but appears to significantly decrease symptoms while increasing a sense of self-efficacy when the client is provided with direct feedback about the administered test. The test becomes a vital part of the client-therapist interaction rather than remaining a mere diagnostic tool.

The review of the literature shows that assessment feedback can have positive effects. First, feedback has been described as rapport-building in the early stages of the therapist-client relationship (Finn \& Tonsager, 1992; Newman \& Greenway, 1997). Consistent with this empirically supported rapport-building hypothesis, some have suggested that sharing specific and relevant feedback reduces client defensiveness and instills client confidence in the helping process, thus contributing to a collaborative working relationship (e.g., Rozensky, Sweet, \& Tovian, 1997; Wills, 1997). Others also have noted the rapport-building function of feedback, particularly when it is delivered in an accurate and empathic manner (Baucom \& Epstein, 1990; Finn, 1996). Thus, it is reasonable to hypothesize that assessment feedback enhances and accelerates rapportbuilding in the therapeutic setting.

Second, assessment feedback has been described as an intervention that enhances self-related processes such as self-understanding, self-verification, positive self-regard, 
and self-awareness (e.g., Allen et al., 2003; Arkowitz, 1992; Finn, 1996). Consistent with the self-enhancement hypothesis, Finn and Tonsager (1997) found empirical support that concrete and accurate assessment feedback addresses basic human motives for selfverification and insight, self-esteem, and self-efficacy. Many clinicians believe that the early enhancement of client self-awareness facilitates the collaborative identification of treatment goals and the motivation to work toward them (e.g., Baucom \& Epstein, 1990). Third, assessment feedback has been described as having motivational effects on clients' willingness to engage in therapy, leading to a more adaptive life style (Miller, 1995). Empirical support for this hypothesis is provided by the studies by Hickman (1997) and Aubrey (1998). Moreover, assessment feedback has been shown to decrease symptomatic distress (Finn \& Tonsager, 1992; Newman \& Greenway, 1997).

In the above discussion, assessment feedback is treated as a variable within a therapeutic context. However, there are differences across the studies in how assessment feedback has been defined. It appears there are several different components that can together comprise assessment feedback. This renders it difficult to identify the specific factor(s) influencing the positive effects and thereby attribute those positive effects to the provision of assessment feedback. In addition, assessment feedback has been operationalized in a heterogeneous manner across studies. Consequently, this heterogeneity has resulted in several unresolved questions that are of interest in this study. What are the "specific elements" (Finn \& Tonsager, 1997) that produce the positive outcomes? Is it the actual information that is provided which has the positive effects? Is it the intensified attention given by the therapist? These questions could be answered by future research in this area. 
Although the above discussion of assessment feedback shows that assessment feedback can positively affect client motivation for treatment and treatment outcome, no definitive conclusions about why this is so can be drawn as of yet. Thus, further empirical evidence is needed. Also, from a theoretical standpoint, an explanatory framework for the effects of providing assessment feedback may be useful.

In the following section, a framework is provided in the context of two theories for the rapport-building and the self-enhancement hypotheses, as well as for the assertion that feedback affects client symptom improvement. Thus, the next section couches these hypotheses within a theoretical framework.

\section{Theoretical Explanations for the Effectiveness of Assessment Feedback}

Swann's self-verification theory. According to McNulty and Swann (1991), people seek feedback about themselves to make their lives controllable and predictable. To reach this goal, people aim to uphold and confirm their self-views, whether positive or negative. Assessment feedback therefore may makes clients feel understood as far as both their strengths and weaknesses are concerned. This may explain some of the positive findings related to rapport-building in a therapeutic setting.

Swann and his colleagues expanded their self-verification hypothesis by applying it to various research questions. Surprisingly, according to Giesler, Josephs, and Swann (1996), people who suffer from clinical depression seek out feedback that confirms their negative views of themselves. This study assessed participants according to their level of depression and self-esteem (high versus low). Participants were then offered a choice between receiving unfavorable and favorable feedback. Results show that $82 \%$ of depressed participants actually chose the unfavorable feedback compared to $64 \%$ of the low self-esteem participants, whereas $25 \%$ of participants scoring high on self-esteem 
chose the positive feedback option. The results highlight the importance of providing feedback in an empathic and therapeutic manner. The study also shows that people do not only accept positive feedback about themselves, but may indeed seek out negative information. The implications for therapeutic intervention are manifold and need further research. However, it appears that there is a tendency to maintain depressive feelings by seeking out negative evaluations about oneself.

Giesler et al. (1996) did not assess participants' self-esteem after the provision of feedback. Therefore, a direct link between the impact of the content of feedback (positive versus negative) cannot be made based on these findings. The results of this study should, however, be considered when providing feedback to clients. Careful attention should be paid to the information provided to the client, as also mentioned by Butcher (1991; see above discussion).

A more recent study also found that people strive for feedback to maintain feelings of self-worth, self-liking and self-competence (Bosson \& Swann, 1999). Bosson and Swann (1999) specifically sought to elucidate the relation between perceived accuracy of feedback, self-views, and choices of feedback. Results showed that the relation between self-view and feedback preference is mediated by the accuracy of feedback. This point is further discussed in the subsequent discussion about the so-called "Barnum Effect."

In summary, Swann's self-verification theory provides a conceptual explanation for the effectiveness of assessment feedback. Accordingly, assessment feedback increases rapport in a therapeutic setting and furthers self-verification. Clients receiving assessment feedback feel understood, increasingly self-aware and verified. 
Festinger's cognitive dissonance theory. Although the research of Swann and colleagues (Bosson \& Swann, 1999; Giesler, Josephs, \& Swann, 1996; McNulty \& Swann, 1991) showed that people seek out feedback about themselves to verify their belief about themselves, Miller attempted to explain the effects of assessment feedback (Miller, 1995; Miller, Sovereign, \& Krege, 1988) by pointing to its therapy motivating effects brought about by a feeling of cognitive dissonance. Clients are more likely to realize how their problems have caused an undesirable situation (interpersonally and intrapersonally) and seek to remedy it. Therefore, clients are more likely to engage in treatment.

According to Festinger (1957), people seek consistency within themselves. Moreover, there is an inconsistency between what people think they know to be true and their behaviors. In other words, if one values higher education, we are likely to seek a college education for ourselves and will also encourage our children to obtain a college degree. However, one does not always follow one's beliefs or act upon them. People engage in unhealthy behaviors in spite of their better judgment (e.g., smoking, drug abuse, poor eating habits). People also continue to make poor mental health decisions against their better judgment.

Sometimes people manage to rationalize poor life choices by making excuses ("I can't help myself;" "Alcohol makes me more sociable;" "I know it's bad, but it's not going to hurt me"). Sometimes, however, these excuses or rationalizations are unsuccessful, and rather than perceiving a feeling of consistency, or consonance, a feeling of inconsistency and distress comes about. Festinger (1957) called this feeling cognitive dissonance. 
Festinger (1957) hypothesized that because this feeling is uncomfortable and can be evidenced by a symptomatic increase, a person will strive to reduce it. Moreover, a person will actively engage in behaviors, which prevent an increase in this feeling of dissonance. Therefore, people should be motivated to escape the feeling of cognitive dissonance and replace it with a renewed sense of consonance. "Cognitive dissonance can be seen as an antecedent condition which leads to activity oriented toward dissonance reduction just as hunger leads to activity oriented toward hunger reduction" (Festinger, 1957, p. 3). Assessment feedback is often provided to the client at the onset of therapy. While reasons for seeking a therapeutic relationship are manifold, the wish to decrease cognitive dissonant feelings is certainly among them. By providing assessment feedback to clients, cognitive dissonance can be reduced, and this may lead to a decrease in symptomatic distress.

To summarize, from a theoretical perspective, two approaches to explain the impact of feedback can be identified. First, the research of Swann and colleagues shows that people have a tendency to seek feedback whether it be positive or negative. Additionally, people seek out such feedback to maintain self-verification, and affect selfesteem by increasing a sense self-liking and self-competence. Within that frame, assessment feedback enhances rapport-building and positively affects self-discovery.

Second, Miller et al. (1988) take a slightly different approach by pointing to the therapy-enhancing impact of feedback. More specifically, Miller (1995), in conjunction with Festinger's (1957) theory of cognitive dissonance, hypothesizes that feedback, when delivered in a therapeutic framework, can motivate clients to engage in therapy. This could further provide an explanatory frame for the empirical findings of symptomatic 
decrease in clients who are provided with assessment feedback (Finn \& Tonsager, 1992; Newman \& Greenway, 1997).

Even though there is growing empirical support for the positive effects of assessment feedback, questions about whether clients only accept accurate feedback or are prone to accept any type of feedback whether it be accurate or bogus have been posed. The phenomenon referred to as the Barnum Effect comes to mind in this context. The following provides a discussion of the research in the area.

\section{The Barnum Effect}

The tendency of people to accept bogus personality feedback has been a major criticism in the appraisal of assessment feedback as a useful and valid therapeutic tool. Earlier research has suggested that people often accept vague, generalized, bogus personality descriptions about themselves (Forer, 1949). This has led to the coining of the term "Barnum Effect." The term was coined by Meehl (1956) to describe the phenomenon of people's acceptance of personality feedback solely on the basis that it supposedly was derived from personality assessment instruments. Such feedback was highly general and had a high base rate accuracy in the general population. The Barnum Effect phenomenon has subsequently been used to explain people's acceptance of horoscopes, tarot card readings, etc.

A thorough review of the literature on the Barnum Effect was conducted by Furnham and Schofield (1987). A critical analysis of the literature in the field showed that general personality descriptions tend to be vague and ambiguous and likely to be accepted as true of oneself based on the general nature of the descriptions. Relatedly, the question whether people can distinguish between true and false personality descriptions has been raised. Earlier research claimed that participants of research studies were not 
able to differentiate between their actual MMPI profile descriptions and those of other people (Sundberg, 1955).

More recent research has cast doubt on the suggested gullibility of participants in such studies (for a review see Furnham and Schofield, 1987). Factors such as testing situations, the nature of feedback statements, and the types of questions posed to participants largely influence their acceptance of feedback. Eliciting the Barnum Effect is therefore dependent on specific factors, and one cannot simply state that participants are overwhelmingly likely to accept favorable personality feedback regardless of its accuracy.

Furnham and Schofield's (1987) literature review further showed that caution is needed when attempting to generalize from studies where bogus Barnum personality statements were used to studies where actual personality profiles, derived from a valid testing tool were used. Moreover, criticism of the methodology of the early studies supporting the Barnum Effect was voiced (Dana, 1982; Furnham \& Schofield, 1987). Criticisms included the mentioning that the findings on the Barnum effect had failed to be replicated consistently. Therefore, findings from studies using bogus Barnum personality statements do not appear readily generalizable to studies using actual assessment feedback.

Ethical questions also have been raised about giving bogus personality feedback to research study participants, as they may seek psychological counseling services at a future date (Dana, 1982). Although the Barnum Effect should not be used as a deterrent from providing accurate personality assessment feedback, Furnham and Schofield's review (1987) showed that study participants' perceptions of the examiner's credibility can impact their acceptance of feedback. Therefore, it may be helpful to rule out possible 
confounding effects of examiner credibility on the acceptance of feedback in studies using actual assessment feedback.

Summary of Literature on Assessment Feedback

In summary, studies conducted on the effects of assessment feedback lend support to its therapeutic value. Not only has feedback been shown to enhance motivation to change behavior (Miller, 1995), it has been shown to positively affect self-enhancement (e.g., increasing client self-verification, self-esteem, self-discovery), rapport between client and therapist, and decreases in symptoms (Allen et al., 2003; Finn \& Tonsager, 1992; Newman \& Greenway, 1997; Worthington et al., 1995). Furthermore, these hypotheses find theoretical support in Festinger's (1957) cognitive dissonance theory and in Swann's self-verification theory (McNulty \& Swann, 1991). However, more research to empirically support these claims is necessary.

Limitations of the empirical findings. Limitations of the existing empirical literature are worth mentioning. Finn and Tonsager (1997) pointed out that future research in the assessment feedback area should concentrate on attempting to generalize the empirical findings to other settings and including more assessors in research designs. Comparing assessment feedback to other therapies and identifying the specific underlying elements can also help increase current understanding of the effects of assessment feedback.

Thus far, neither Finn and Tonsager (1992), nor Worthington et al. (1995), nor Newman and Greenway (1997) can definitely attribute the positive results found solely to the provision of feedback. A more precise operationalization of the actual feedback session's therapeutic elements would be beneficial. The Finn and Tonsager (1992) and Newman and Greenway (1997) studies' approach to providing assessment feedback are 
based on Finn's (1996) model. Specifically, the assessment feedback conditions in these studies were said to be based on the approach developed by Finn (1996) and included information about the MMPI-2, interpretation of the MMPI-2 profile and results, and answers to clients' questions about future treatment and/or the MMPI-2. All of this was done in a collaborative, empathic and reflective manner. This approach includes a variety of therapeutic elements. The positive findings could be therefore due to any of those elements individually, or in combination with one another. Without a more precise and clear definition, it is difficult to ascertain what exactly was done during the feedback sessions. More importantly, it is difficult to say which one of the elements is primarily responsible for the positive results.

Further, in the Worthington et al. (1995) study, only one of the groups had direct interaction in a counseling setting with the investigator. Even though the study controlled for the investigator's competency, no firm conclusions can be drawn about whether the positive effects were due to the interaction with the investigator, the information provided, or both (or neither). Additionally, the "attention only" control group design may not be the most credible way to test for the efficacy of assessment feedback. The question whether another counseling approach may have produced similar results following the administration of a personality inventory cannot be answered with such a design. Thus, a study using an alternative approach other than an "attention only" group may further elucidate the actual effects of assessment feedback. This is done in the present study. In addition, Allen et al. (2003) sought to further elucidate the factors responsible for the positive effects of assessment feedback. However, a more rigorous methodological design is needed to adequately substantiate the study`s claims. Therefore, 
the question about what specific elements lead to positive results remains unanswered, a point weakening the internal validity of the studies in the area of assessment feedback.

Also, the efficacy of assessment feedback has not been established sufficiently thus far. Assessment feedback has only been tested in designs using "attention only" comparison control groups. Therefore, the designs used in the empirical research do not allow us to draw definite conclusions about the efficacy of providing assessment feedback. Additionally, the previous studies in the area (Allen et al., 2003; Finn \& Tonsager, 1992; Newman \& Greenway, 1997) did not use multiple assessors. Future research would benefit from having several assessors deliver assessment feedback. Thus, this also was done in the present study. By so doing, the study's findings would be more independent of one particular investigator, and thus would also increase its external validity.

Rationale for using the Millon Clinical Multiaxial Inventory-III ( MCMI-III; Millon, Millon, \& Davis, 1997). Both the Finn and Tonsager (1992) and Newman and Greenway (1997) studies used the MMPI-2 as their assessment tool. The MMPI-2 is one of the most widely used personality inventories (Strack, 1999). However, with 567 questions, it is also very lengthy, thus leading to client fatigue. Moreover, interpretation of the MMPI-2 requires substantial training and its results are not readily compatible with the DSM-IV.

In an effort to make assessment feedback more efficient (Finn \& Tonsager, 1997), using a less item and time-lengthy and interpretation-arduous personality inventory could be beneficial. Thus, this study used a shorter and more efficient clinical personality assessment measure. Specifically, this study used one of the Millon inventories as its assessment tool. 
Since its development in 1977, the MCMI has become one of the most widely used personality inventories (Strack, 1999). Only the Rorschach and the MMPI-2 have received more research interest (Strack, 1999). There are currently over 400 empirical studies about the MCMI (Strack, 1999). According to Retzlaff (1997), the MCMI-III particularly lends itself for use as a treatment planning tool. This is because it is DSM-IV compatible, which thereby allows clinicians to combine assessment with treatment planning. With its emphasis on holistic client conceptualization, the MCMI-III strives to combine both the nomothetic and ideographic positions (Millon \& Davis, 1997). Theory, taxonomy, assessment, and intervention domains are integrated and, while placing constraints on one another, also serve as validity checks for one another.

Millon stresses that social factors interact with personality attributes to produce Axis I disorders (Millon \& Davis, 2000). The more adaptive and flexible a person's personality, the greater the likelihood that psychosocial stressors are dealt with appropriately and without manifestation of maladaptive behavior. The more inflexible and less adaptive a person's personality style, the greater the impact of stressful life events leading to psychological distress. Within this framework, Millon refers to personality as the psychological immune system (Millon \& Davis, 2000). A person's personality style and inherent repertoire of coping mechanisms can therefore influence psychological well-being. Millon further refers to personality as the "cardinal organizing principle through which psychopathology should be understood" (Millon \& Davis, 2000, p. 9).

Within this frame, a person's interpersonal style is determined by his or her personality patterns, which in turn can greatly contribute to perceived stress increases in relationships. Although complaints about a decrease in relationship satisfaction often 
parallel Axis I symptomatic distress, assessing personality patterns can serve as a useful tool in counseling settings (Truitt, 1999). Therefore, the MCMI-III is an ideal assessment instrument for efficient personality assessment that can provide information about interpersonal styles. The psychometric characteristics of the MCMI-III are detailed in Appendix A.

\section{The Present Study}

This study aims to extend empirical research on assessment feedback by addressing some of the limitations of past studies (Allen et al., 2003; Finn \& Tonsager, 1992; Newman \& Greenway, 1997). Past assessment feedback studies have examined the effects of assessment feedback and reported positive effects. However, it is unclear what the most significant influences are. One possibility is that the feedback session and attention from the investigator in a therapeutic context has positive effects. Another possibility may be that the actual information provided by the investigator brings about the positive effects. In an effort to heed the call of Finn and Tonsager $(1992,1997)$ to study more clearly the "specific therapeutic elements (Finn \& Tonsager, 1992, p. 284)," to help "minimize nonessential components (Finn \& Tonsager, 1992, p. 284), " and provide a more efficient way of providing assessment feedback, this study was conducted. Specifically, this study tested the effects of one such specific element, the actual information provided during the feedback session following the test administration. In doing so, five main methodological issues were addressed which went largely unaddressed in past studies (Allen et al., 2003; Finn \& Tonsager, 1992; Newman \& Greenway, 1997).

First, this study sought to identify a specific element of assessment feedback viewed as responsible for the positive effects found in previous studies (Allen et al., 
2003; Finn \& Tonsager, 1992; Newman \& Greenway, 1997), interpretive informationor, to be more specific, the objective information gathered from a personality inventory. In other words, this study sought to answer the question whether it is the information provided during the feedback session that is responsible for the positive effects (e.g., rapport-building, self-enhancement, and symptomatology).

Second, although previous studies have investigated the effects of assessment feedback by using an experimental group and comparison control group in which the treatment group was provided feedback whereas the comparison control condition was given "attention only," this study included an additional experimental group to further test the impact of investigator warmth and empathy. Thus, in addition to the "attention only" comparison control group, a group was added which provided participants with a reflective, empathetic, but non-leading investigator who did not provide information about the test results. This group was designed to help answer the question of what causes the positive effects in an assessment feedback situation. This study sought to do so by testing the assessment feedback approach vis-à-vis another counseling approach. Thus, this study had three groups: a Feedback group, a Reflective-Counseling group, and a NoFeedback group.

Third, this study assessed the influence of the conditions on participants' perceptions of investigator credibility. The literature on the Barnum Effect (Furnham \& Schofield, 1987) has indicated that participants' perceptions of investigator credibility can influence their level of acceptance of feedback in that participants are more likely to accept feedback from investigators to whom they attribute greater credibility. Thus, this study assessed whether investigator credibility across the three conditions was significantly different on this factor. 
Fourth, and an additional methodological strength, this study included an integrity check to ensure that the appropriate content of material delivered in each of the three different groups. In previous research, such an integrity check had not been completed, thus limiting internal validity (e.g., Finn \& Tonsager, 1992). Specifically, this study sought to clearly dictate what should be said during the individual sessions and what should not be said. Thus, this study used verbal response mode categories to reflect the conditions' contents. These verbal response modes were drawn from a list of counseling skills/tools devised by Hill and O'Brien (1999).

Fifth, to increase external validity and allow for increased generalizability, this study used multiple assessors. The previous studies (Allen et al., 2003; Finn \& Tonsager, 1992; Newman \& Greenway, 1997) used only one assessor. Including multiple assessors into this study's design was done to further increase the study's methodological strength by increasing external validity and making the results more generalizable.

In sum, the study's research questions were:

Research Question 1: Will participants in the Feedback group report significantly better rapport with their investigator (a more positive relationship, greater sense of acceptance, less negative feelings about the assessment) than participants in the Reflective-Counseling and No-Feedback groups as found in previous research (Allen et al., 2003; Finn \& Tonsager, 1992; Newman \& Greenway, 1997)?

Research Question 2: Will participants in the Feedback group report a significantly greater sense of self-enhancement (self-esteem, self-verification, selfdiscovery; see McNulty, \& Swann, 1991) than participants in the Reflective-Counseling and No-Feedback groups, as found in previous studies (Allen et al., 2003; Finn \& Tonsager, 1992; Newman \& Greenway, 1997)? 
Research Question 3: Will participants in the Feedback group report a significant decrease in symptoms when compared to participants in the Reflective-Counseling and No-Feedback groups as seen in previous studies (Allen et al., 2003; Finn \& Tonsager, 1992; Newman \& Greenway, 1997)?

Research Question 4: Will there be significant differences in participants' evaluation of assessor credibility among the three groups (Feedback, ReflectiveCounseling, No-Feedback)?

These research questions were tested in the context of a relationship workshop. This workshop provided a forum for testing the effects of MCMI-III assessment feedback. Clients seeking to enhance their romantic relationships were provided with assessment feedback about their interpersonal personality styles.

\section{METHODS}

\section{Participants}

The study included 89 participants ( 62 females; 27 males). The mean age of the participants was 24.4 years and ranged from 18 to 46 years of age ( $\mathrm{SD}=6.4$ years). In terms of ethnicity, $56(62.9 \%)$ of the participants identified themselves as Hispanic/Latino, 20 (22.5\%) White, 4 (4.5\%) Black (not of Hispanic origin), 3 (3.4\%) Haitian, 3 (3.4\%) Asian Pacific Islander, 2 (2.2\%) Jamaican, and 1 participant was of another ethnic background.

Participants were recruited from the local and FIU community via newspaper ads and flyers. The flyer invited young adults to contact the Youth and Family Development Lab at Florida International University if they were interested in working on relationship difficulties and wanted to find out "more about themselves." The relationship workshop was offered to enhance satisfaction within romantic relationships. A copy of the flyer 
used can be found in Appendix B. During the first telephone contact, potential participants were informed about the nature of the clinical workshop, which was to be held over a 4-week period, and that an assessment would be conducted before the beginning of the workshop. Interested parties were given an appointment for a meeting with an assessor during which time the assessment took place.

\section{Procedure}

Preassessment. At the beginning of the assessment session, all participants were asked to sign an informed consent form. The consent form provided the participants with general information about the nature and purpose of the study. Participants were told that their participation was voluntary and would require a total of 2 hours of their time, divided into two 1-hour meetings with an assessor over the course of two weeks. At the conclusion, participants would then be asked to participate in the above-mentioned workshop. Participants were also informed that their participation in this assessment and subsequent individual session with the assessor was not contingent on their participation in the workshop and vice-versa. Copies of the consent forms can be found in Appendix C

Following the signing of the informed consent form, all participants were asked to complete a sociodemographic information form. In addition, all participants were asked to complete a self-esteem measure and a measure assessing bothersome bodily feelings/sensations (symptomatology), subsequently. These two measures were the only measures administered twice in this study. After completing these measures, participants were then asked to take the personality inventory, the MCMI-III.

The individual sessions with the investigator were taped so that treatment integrity could be assessed. Participants signed a form consenting to the audio taping of 
the session at the beginning of the second meeting, before the individual session with the assessor.

Feedback group. Participants in the Feedback group received assessment feedback based on their MCMI-III profiles/testing results during the second meeting with the same assessor who administered the questionnaires during the first meeting. This feedback session was approximately 20 minutes in length. During this time, the investigator showed the participant a computer generated print-out of their MCMI-III profile elevations. Feedback was based on the interpretative reports provided by the publisher of the test, Pearson Assessments, based on Theodore Millon's personality conceptualizations. Each participant was provided with the objective information gathered from their individual MCMI-III administration. To avoid clinical jargon, a summary of the interpretative report was created by changing the language, but not the content, of the report to be more easily understood by laypeople. To avoid diagnostic labeling, the clinical descriptors on the profile reports of the MCMI-III were changed to Millon's personality style descriptors. Thus, rather than informing a participant that his or her personality style was narcissistic, for example, the term asserting, was used. A complete listing of the clinical personality labels vs. the personality styles can be found in Appendix $\mathrm{D}$. Thus, because the hypothesized active element in bringing about the positive effect of assessment feedback is interpretative test information (see Finn \& Tonsager, 1992), according to Hill and O'Brien's response modes (1999), participants of the Feedback group received Information and Interpretation of the test results during this session.

Reflective-Counseling group. Participants in the Reflective-Counseling group did not receive assessment feedback based on their MCMI-III profiles/testing results during 
the second meeting with the same assessor who administered the questionnaires during the first meeting. Rather, participants in the Reflective-Counseling group were asked to tell the assessor what meaning and/or significance they can ascribe to the MCMI-III testing experience they just underwent. Participants in this group were not invited to look at a profile of their assessment results. Furthermore, the assessor refrained from providing information about the MCMI-III to the client. This session was approximately 20 minutes in length. The focus during this session was on allowing the client to verbalize his or her impressions about the test and what information they perceived to have gathered from it.

The assessor maintained a reflective, empathic and non-directive approach according to Rogerian counseling techniques during the session. According to Hill and O'Brien's response modes (1999), participants in the Reflective-Counseling group received Open Questions, Reflection of Feeling and Reflection of Content during this session.

No-Feedback group. Participants in the No-Feedback group did not receive any personal information about their individual profiles/testing results during the second meeting with the same assessor who administered the questionnaires during the first meeting. Participants in this group also were not invited to elaborate on their subjective impressions about having taken the test. Participants in this group received information about what kind of test they took. Such information was general in nature. The assessor was warm and friendly toward the participants. This session was approximately 20 minutes in length. The focus of the session was on providing the participants with attention equal in length to the attention participants of the two other groups received. Participants had an opportunity to discuss any concerns about the study. According to Hill and O'Brien (1999), participants received Information during this session. The 
assessor did not make any interpretive statements, and refrained from Reflection of Feeling, Content, or Open Questions.

Postassessment. Following the individual sessions, participants were asked to complete the post assessment tests. The post assessment test battery consisted of a selfesteem measure, a measure to assess symptomatology, an assessment questionnaire, and a counselor perception measure. The total time needed to complete the questionnaires was about 25 minutes. Participants of the Feedback group completed the post assessment battery after having received feedback. Participants of the Reflective-Counseling and NoFeedback groups had the option of receiving feedback about their MCMI-III results thereafter or make another appointment, depending on their schedules, should they express an interest.

Assessors. Participants were assessed by three female doctoral-level and one female master-level graduate students in psychology (a total of 4 graduate students). There were 2 Hispanic assessors, 1 African American assessor, and 1 Non-Hispanic White assessor. The same assessor saw the participant during both meetings. Assessors were randomly assigned to the three conditions (Feedback, Reflective-Counseling, NoFeedback). All assessors were trained in the proper administration of the MCMI-III, questionnaires and content of the individual sessions following assessment by Andrea Allen.

Individual session integrity. Individual session integrity was assessed by means of a checklist listing the response mode categories by Hill and O'Brien (1999).

Undergraduate students, blind to the study's research questions, and who had been trained in the Hill and O'Brien (1999) verbal response modes, rated the session tapes by making frequency counts next to the appropriate columns. For example, Interpretation is 
supposed to provide the participant with a new framework to feelings, behaviors, or problems. Interpretation offers the participant with "a conceptual framework" (Hill \& O’Brien, 1999).

The verbal response mode, Reflection of Feeling, is supposed to provide the participant with a rephrasing or repeating of his or her statements. The verbal response mode, Open Question, invites participants to explore their feelings, rather than asking for specific answers. Open Questions can be phrased by beginning a sentence with "Tell me..." or by asking "How do you feel about that?" (Hill \& O'Brien, 1999; a description of the verbal response modes along with a session rating sheet can be found in Appendix E.

\section{Measures}

A copy of the measures can be found in Appendix $F^{1}$.

Millon Clinical Multiaxial Inventory-III (MCMI-III). The MCMI-III (Millon, Davis, \& Millon, 1997) is the newest version of the Millon Clinical Multiaxial Inventory. This clinical test was revised due to the emergence of the DSM-IV (American Psychiatric Association, 1994) to make its scales reflective of the changes that had been made on the Axis II (Personality Disorders) in the DSM-IV. The MCMI-III is a 175-item, true/false self-report inventory assessing 14 personality patterns and 10 clinical syndromes (Millon et al., 1997). A baserate score (BR) of 60 was set as the median raw score obtained by all patients in the normative sample. BR scores of 75 indicate that criteria for a particular disorder are met. Scores of 75 to 84 indicate that there are clinically significant personality traits. Scores of 85 and above suggest a disorder. For the clinical syndrome

\footnotetext{
'The BSI can be obtained from its publisher, Pearson Assessments. The Assessment Questionnaire can be obtained from Dr. Stephen Finn, Center for Therapeutic Assessment, University of Austin, TX.
} 
scales, BR scores of 75 to 84 indicate the presence of a syndrome, and BR scores of 85 and above indicate the prominence of a syndrome. Raw scores for all scales except for the Disclosure scale (Scale X) are computed by adding up the number of items endorsed for the scales with the proper weights (Millon, et al., 1997).

Alpha coefficients have been found to range from .66 for Scale 7 to .90 for Scale CC. Twenty out of 26 scales have alpha coefficients that surpass .80 . The test-retest reliability correlations were conducted with 5 and 14 days retest intervals. The correlations range from .82 for Scale $\mathrm{Z}$ to .96 for Scale $\mathrm{H}$ with a median stability coefficient of .91 (Millon et al., 1997).

With regard to validity, correlations between the MCMI-III and collateral testing instruments (instruments that are theoretically related to the underlying construct of the particular scale) were computed from the BR scores of the MCMI-III and scores from collateral instruments. These collateral instruments were the Beck Depression Inventory (BDI), General Behavior Inventory (GBI), Michigan Alcoholism Screening Test (MAST), Impact of Events Scale (IOES), State-Trait Anxiety Inventory (STAI), Symptom Checklist-90-Revised (SCL-90-R), and the MMPI-2. Relatively high correlations, Major Depression (.74) and Dysthymia (.71), were found between the BDI and a number of MCMI-III scales except for the Histrionic Scale (-. 49), Narcissistic Scale (-. 40), and Compulsive Scale (-. 30). High correlations also were found with the Depressive (.56), Borderline (.56), Self-Defeating (.53), and Schizoid scales (.53). Less strong relations were established between the Aggressive (.22) and Antisocial (.20) personality disorders scales. A detailed description of the MCMI-III's scales and psychometric properties can be found in Appendix B. 
Counselor Perception Measure (CPM). The CPM (McLennan, 1990), a measure

of counselor credibility, served as a manipulation check, as well as an additional measure of rapport-building. The experimental manipulations in previous studies (Finn \& Tonsager, 1992; Newman \& Greenway, 1997) controlled for the impact of both assessment and investigator attention. This study included the CPM as an additional check on the impact of investigator attention + specific feedback, versus investigator attention that included no specific feedback, on participants' perceptions of investigator credibility. Participants were provided with 12 positive, descriptive adjectives (such as "expert," "confident," and "understanding") and were asked to rate the therapist/investigator on those adjectives along a 1 to 7 scale.

The CPM has two subscales, the Acceptance and Competence subscales. The Acceptance subscale includes items 3-7 (accepting; caring; sensitive; supportive; understanding); the Competence subscale includes items 8-12 (competent; confident; direct; expert; knowledgeable). Items 1 (friendly) and 2 (firm) serve as fillers. The items of the CPM are added together to arrive at a total score; items for the two subscales, Acceptance and Competence, are added separately to arrive at subscale ratings. A high score indicates a positive rating of the counselor's credibility. This score was used to assess participants' perceptions of the assessors' credibility. Scores for the total scale can range from 12 to $84 ; 12$ indicating the lowest and 84 indicating the highest possible score. The subscale, Acceptance, was used as an additional measure of rapport-building. Scores for the subscales can range from 5 to 35 , with 5 indicating the lowest possible score and 35 indicating the highest possible score. Alpha coefficients for the Acceptance and Competence subscales were found to be .84 and .81, respectively (McLennan, 1990). Test-retest reliability, using a 10-week interval, was found to be .66 for the Acceptance 
subscale and .68 for the Competence subscale. Validity studies showed that the CPM subscales were correlated with the subscales of the Counselor Rating Form-Short Version (CRF-S; Atkinson \& Wampold, 1982). Specifically, correlation coefficients were $r=.69$ between the CPM's Acceptance subscale and the CRF-S's Attractiveness subscale, and $r=.70$ between the CPM's Competence subscale and the CRF-S's Expertness subscale. Assessment Questionnaire-2 (AQ-2; Finn \& Tonsager, 1992, 1994). The AQ-2 (Finn \& Tonsager, 1994) has 48 questions in total. Participants are asked to rate each questions on a 5-point scale ranging from "Strongly Disagree" (1), to "Strongly Agree" (5). The scale has four subscales (New Self-Awareness-13 items; Positive Accurate Mirroring-12 items; Positive Relationship with the Assessor-12 items; Negative Feelings about the Assessment-11 items). This questionnaire was used in the previous studies by Finn \& Tonsager (1992), Newman \& Greenway (1997) and Allen et al. (2003).

Item number 1 is reversed scored before the items of each scale are added together and divided by the number of items in each scale. In addition to the four scale factors, a General Satisfaction score (GS) is computed. The formula for arriving at the GS is:

$\mathrm{GS}=(.17)$ Factor $1 \mathrm{z}+(.39)$ Factor $2 \mathrm{z}+(.37)$ Factor $3 \mathrm{z}-(.17)$ Factor $4 \mathrm{z}$. , where

Factor $1 z=$ Client's score on Factor 1 - Mean Sum of Factor 1 divided by the Standard Deviation on Factor 1, etc.

A high score indicates a positive rating of the assessment experience. Scores for the subscales can range from 11 to 65 , with 11 indicating the lowest possible score and 65 indicating the highest possible score. Scores for the total scale can range from 48 to 240 , with 48 indicating the lowest possible score and 240 indicating the highest possible score. 
Alpha coefficients for the scales are .84 (New Self-Awareness), .88 (Positive Accurate Mirroring), .90 (Positive Relationship with Assessor), and .92 (Negative Feelings about the Assessment). Test-retest reliability, using a two-week interval, ranges from .75 to .84 (Finn \& Tonsager, 1992, 1994), with New Self-Awareness .78, Positive Mirroring .75, Positive Relationship with the Assessor .84, and Negative Feelings about the Assessment .81. In this study, all of the 4 subscales, New Self Awareness, Positive Accurate Mirroring, Positive Relationship with the Experimenter, and Negative Feelings about the Assessment, plus the General Satisfaction Score (GS) were used. Specifically, the New Self-Awareness subscale of the AQ-2 (Finn \& Tonsager, 1992, 1994) was used to test the whether assessment feedback enhances clients' sense of self-discovery. The New Self-Awareness scale reflects participants' view that they learn information about themselves that they regard as potentially useful (e.g., "the investigator introduced me to new aspects of myself').

The second subscale, Positive Accurate Mirroring, of the AQ-2 (Finn \& Tonsager, 1992, 1994) was used to test whether assessment feedback increases self-verification. The Positive Accurate Mirroring scale indicates whether participants' perceptions about themselves are reaffirmed and they feel proud, secure or important after the testing experience (e.g., "this experiment captured the 'real' me").

The other two subscales, Positive Relationship and Negative Feelings of the AQ-2 (Finn \& Tonsager, 1992, 1994), were used to test whether assessment feedback accelerates rapport-building. The Positive Relationship with the Investigator scale indicates participants' positive feelings between themselves and the investigator (e.g., "it was easy to trust the investigator"); the Negative Feelings about the Assessment scale indicates whether participants' felt hurt, judged or exposed by the experience. 
Self-Liking/Self Competence Scale Revised (SLCS-R; Tafarodi \& Swann, 1995, 2001) was used as an additional measure for assessing the impact of assessment feedback on self-enhancement. The SLCS-R was administered at Preassessment and at Postasssessment. The SLCS-R, a 16-item scale, measures global self-esteem as a twodimensional construct. Participants are asked to rate themselves using a Likert-type scale ranging from 1 (strongly disagree) to 5 (strongly agree). The scale has two 8 items subscales assessing Self-Liking (i.e., a sense of self-worth) and Self-Competence (i.e., a sense of personal efficacy; described below) which are balanced with positive and negative items (Tafarodi \& Swann, 2001).

The two factors are computed by reverse scoring items $1,6,7,15$ for the SelfLiking factor, and $8,10,13,16$ for the Self-Competence factor. Items are then added to arrive at total factor scores. A high score indicates a high level of self-liking/selfcompetence. Scores for the subscales can range from 8 to 40 , with 8 indicating the lowest possible score and 40 indicating the highest possible score.

The SLSC-R yields two factors: a Self-Liking factor, comprised of items 3, 5, 9, $11,1,6,7$, and 15 (alpha coefficient $=.88$ ), and the Self-Competence factor, comprised of items $2,4,12,14,8,10,13$, and 16 (alpha coefficient $=.79)$. Test-retest reliability scores using a 3-month interval are .78 for Self-Competence and .75 for Self-Liking. These scores, after having been corrected for attenuation due to internal inconsistency, translate into 3-month stability estimate scores of .94 for Self-Competence and .83 for Self-Liking (Tafarodi \& Swann, 2001).

A multitrait-multimethod approach was used to establish the SLCS-R's validity. In doing so, multiple indicators of self-liking and self-competence were tested using 
Confirmatory Factor Analysis (Tafarodi \& Swann, 2001). Specifically, correlations between different informant's ratings are $r=.35$ for the Self-Competence factor, and $r=$ .45 for the Self-Liking factor.

Brief Symptom Inventory (BSI; Derogatis, 1993) was used to assess the participants' level of symptomatic distress. The BSI was administered at Preassessment and at Postassessment. The BSI is a shorter version of the Symptom Checklist 90 Revised (SCL-90-R; Derogatis, 1983). It contains 53 items and takes about 10 minutes to complete. Participants are asked to rate their distress on a 5-point scale ranging from "Not at all" (0) to "Extremely" (5). The BSI measures psychopathology along 9 primary symptom dimensions (Somatization, Obsessive-Compulsive, Interpersonal Sensitivity, Depression, Anxiety, Hostility, Phobic Anxiety, Paranoid Ideation, Psychoticism) and 3 global ones, a Global Severity Index (GSI), a Positive Symptom Distress Index (PSDI), and the Positive Symptom Total (PST). The purpose of the global indices is to provide a single score of the level or depth of psychopathology. According to the developer of the test, the GSI should be used when a single summary measure is needed (Derogatis, 1993). Therefore, this study used the GSI as a factor in assessing symptomatology. To arrive at a score, item responses are first transferred to a profile sheet. To arrive at the raw symptom dimension scores, all the non-zero distress score items are added to arrive at the summed distress scores for the 9 symptom dimensions. After that, each summed distress score is divided by its respective number of items (e.g., for Phobic Anxiety, divide by 7).

A grand total of the summed distress scores is obtained and divided by 53 to arrive at the Global Severity Index. The raw scores are converted into $t$-scores by referring to the manual's norms (Derogatis, 1993). Adjustments for missing data are 
made by decreasing the numerator for each dimension by the number of items missing. Alpha coefficients range from .77 (Psychoticism) to .90 (Depression), with .86 for three dimensions (Somatization, Obsessive-Compulsive; Interpersonal Sensitivity), .85 (Anxiety), .84 (Hostility), .82 (Phobic Anxiety), and .80 (Paranoid Ideation). Test-retest values using a 1-week interval, range from .78 (Hostility) to .90 (Phobic Anxiety). The values for the other dimensions are .86 (Paranoid Ideation, Somatization), .85 (Obsessive-Compulsive), .84 (Psychoticism), .83 (Interpersonal Sensitivity), .82 (Depression), and .80 (Anxiety).

Studies establishing convergent validity have been conducted using the MMPI by computing alpha coefficients between the BSI symptom dimensions and the MMPI scales. Alpha coefficients range from .63 (Interpersonal Sensitivity) to .72 (Depression). Furthermore, the scale has been shown to be sensitive to change in clinical and medical settings (see Derogatis, 1993, for a detailed discussion).

\section{RESULTS}

\section{Group Comparability}

Tables 1 and 2 present the sociodemographic characteristics of the three groups (Feedback, Reflective-Counseling, No-Feedback). Group differences along the sociodemographic variables across the three conditions were analyzed using chi-square tests, and analyses of variance (ANOVAs). Comparisons of sociodemographic variables across conditions included age, gender, and ethnicity. There were no significant differences on any of the sociodemographic variables across the groups.

Means and standard deviations on the Rapport-Related, Self-Enhancement, and Symptomatology measures are presented in Table 3. Multivariate and univariate analyses of variance on the Rapport-Related, Self-Enhancement, and Symptomatology measures 
are presented in Tables 4, 5, 6, and 7. Means and standard deviations on the variables used to assess Treatment Integrity are displayed in Table 7. Multivariate and univariate analyses of variance of the Treatment Integrity variables and Assessor Credibility measure are displayed in Table 8.

\section{Rapport-Building}

Research Question 1: Will participants in the Feedback group report significantly better rapport with their investigator (a more positive relationship, less negative feelings about the assessment, greater sense of acceptance) than participants in the ReflectiveCounseling and No-Feedback group as found in previous research (Allen et al., 2003; Finn \& Tonsager, 1992; Newman \& Greenway, 1997)?

A one-way multivariate analysis of variance (MANOVA) was conducted to determine the effect of the three conditions (Feedback, Reflective-Counseling, NoFeedback) on the two subscales of the AQ-2, Positive Relationship with the Investigator (PRI) and Negative Feelings about the Assessment (NFA). Results revealed that there was a significant main effect of condition, with Roy's Largest Root $F(2,86)=4.39, p=$ $.015, \mathrm{y}^{2}=.093$.

Analyses of variance (ANOVA) on each of the dependent variables were conducted as follow-up tests to the MANOVA with an adjusted alpha level of .025 . The ANOVA on the Positive Relationship with Investigator subscale (PRI) was significant, $F$ $(2,86)=4.38, p=.015, \mathrm{y}^{2}=.092$. The ANOVA on the Negative Feelings about the Assessment subscale (NFA) was nonsignificant, $F(2,86)=.573, p=.566, \mathrm{y}^{2}=.013$.

Post hoc analyses to the univariate ANOVA for the Positive Relationship with Investigator consisted of conducting pairwise comparisons using Bonferroni tests. Results showed that there were significant differences between the Feedback and No-Feedback 
groups, $p=.012$. Scores for participants of the Feedback group were higher than for participants of the No-Feedback group. There were no significant differences between the Feedback and Reflective-Counseling groups, nor between the Reflective-Counseling group and the No-Feedback group.

A one-way analysis of variance (ANOVA) was conducted to determine the effect of the three conditions (Feedback, Reflective-Counseling, No-Feedback) on the Acceptance subscale of the CPM. Results revealed that there was a significant main effect of condition, $F(2,86)=4.16, p<.019, \mathrm{n}^{2}=.088$.

Post hoc analyses for the Acceptance subscale showed that there were significant differences between the Reflective-Counseling and No-Feedback groups, $p=.021$. Scores for participants in the Reflective-Counseling group were higher than for participants in the No-Feedback group. There were no significant differences between the Feedback and Reflective-Counseling groups, nor between the Feedback and NoFeedback groups.

A one-way analysis of variance (ANOVA) was conducted to determine the effect of the three conditions (Feedback, Reflective-Counseling, No-Feedback) on the General Satisfaction Score of the AQ-2 (GS). Results revealed that there was a significant main effect of condition, $F(2,86)=15.96, p<.001, \mathrm{y}^{2}=.271$.

Post hoc analyses for the General Satisfaction Score (GS) showed that there were significant differences between the Feedback and Reflective-Counseling groups, $p=$ .003. Scores for participants of the Feedback group were higher than for participants of the Reflective-Counseling group. Significant differences also were found between the Feedback and No-Feedback groups, $p<.001$. Scores for participants of the Feedback group were higher than for participants of the No-Feedback group. Further, significant 
differences were found between the Reflective-Counseling and No-Feedback groups, $p=$ .038. Scores for participants of the Reflective-Counseling group were significantly higher than for participants of the No-Feedback group.

\section{Self-Enhancement}

Research Question 2: Will participants in the Feedback group report a significantly greater sense of self-enhancement (self-esteem, self-verification, selfdiscovery; see McNulty, \& Swann, 1991) as found in previous studies (Allen et al., 2003; Finn \& Tonsager, 1992; Newman \& Greenway, 1997)?

Self-esteem. A repeated measures Multivariate Analysis of Variance (RMANOVA) was used to analyze the results of the two factors of the self-esteem scale, SLCS-R, since the SLCS-R was given at two measurement points (preassessment and postassessment), looking at effects of time (before administration of the MCMI-III; after Feedback/Reflective-Counseling/No-Feedback), condition, and time by condition interaction. Results revealed that there was no main effect of group, with Roy's Largest Root, $F(2,86)=1.44, p=.244, \mathrm{y}^{2}=.032$, no main effect of time, with Roy's Largest Root, $F(2,85)=1.38, p=.257, \mathrm{n}^{2}=.032$, but a marginally significant time by condition interaction, with Roy's Largest Root, $F(2,86)=2.84, p=.064, \mathrm{y}^{2}=.062$.

Since there was a marginally significant multivariate time by condition main effect, repeated measures ANOVAs for time by condition interaction were conducted. Results revealed a marginally significant time by condition effect for the self-competence factor, $F(2,86)=2.77, p=.068$. Results for the self-liking factor were non-significant, $F$ $(2,86)=1.26, p=.288$. Further, pairwise comparisons using Bonferroni tests were conducted. Results were significant, $p=.017$, indicating a decrease in the scores of the self-competence factor for participants of the No-Feedback group from pre to post. 
Self-Verification and Self-Discovery. A one-way multivariate analysis of variance (MANOVA) was conducted to determine the effect of the three conditions (Feedback, Reflective-Counseling, No-Feedback) on the two subscales of the AQ-2, Positive Accurate Mirroring (PAM) and New Self-Awareness (NSA). Results revealed a significant main effect of condition, $F(2,86)=19.414, p<.001, \mathrm{y}^{2}=.311$.

Analyses of variance (ANOVA) on each of the dependent variables were conducted as follow-up tests to the MANOVA with an adjusted alpha level of .025 . The ANOVA on the Positive Accurate Mirroring (PAM) was significant, $F(2,86)=15.403$, $p<.001, \mathrm{y}^{2}=.264$. The ANOVA on the New Self-Awareness subscale (NSA) also was significant, $F(2,86)=18.054, p<.001, \mathrm{n}^{2}=.296$.

Post hoc analyses for the univariate ANOVA for the Positive Accurate Mirroring and New Self-Awareness subscales consisted of conducting pairwise comparisons using Bonferroni tests. Results for tests on both variables revealed that there were significant differences between the Feedback group and No-Feedback group, $p<.001$. For both subscales, scores for participants of the Feedback group were significantly higher than for participants of the No-Feedback group. Significant differences were also found between the Feedback group and Reflective-Counseling group, $p<.001$, for both subscales. Scores for participants of the Feedback group were higher than for participants in the Reflective-Counseling. No significant differences were found between the ReflectiveCounseling group and the No-Feedback group for both subscales.

\section{Symptom Decrease}

Research Question 3: Will participants in the Feedback group report a significant decrease in symptoms when compared to participants in the Person-Centered and No- 
Feedback groups as found in previous studies (Allen et al., 2003; Finn \& Tonsager, 1992; Newman \& Greenway, 1997)?

A repeated measures Univariate Analysis of Variance (RANOVA) was used to analyze the results of the BSI, since the BSI was given at two measurement points (preassessment and postassessment), looking at effects of time (before administration of the MCMI-III; after Feedback/Reflective-Counseling/No-Feedback), condition, and time by condition interaction. Results revealed a significant main effect of time, with Roy's Largest Root $F(1,85)=41.22, p<.001, \mathrm{n}^{2}=.327$, indicating a significant decrease in scores over time across the three groups. There was neither a significant main effect for condition, with $F(2,85)=.353, p=.704, \mathrm{y}^{2}=.008$, nor a significant time by condition interaction, with Roy's Largest Root $F(2,85)=.069, p=.934, \mathrm{y}^{2}=.002$.

\section{Assessor Credibility}

Research Question 4: Will there be significant differences in participants' evaluation of assessor credibility among the three groups (Feedback, ReflectiveCounseling, No-Feedback)?

Results of the CPM testing the effects of the assessor showed that there were no significant differences across the three groups. The results of the ANOVA were $F(2,86)$ $=2.13, p=.126, \mathrm{y}^{2}=.047$

\section{Treatment Integrity}

To test whether the three conditions were distinct from each other based on the criteria described above (Hill \& O'Brien, 1999), a multivariate analysis of variance (MANOVA) was conducted on $25 \%$ of the cases $(\mathrm{N}=25)$.

Results revealed that there was a main effect of condition with Roy's largest Root $F(7,17)=28.77, p<.001, \mathrm{y}^{2}=.922$. Analyses of variances (ANOVA) on each of the 
dependent variables were conducted as follow-up tests to the MANOVA with an adjusted alpha level of .007. The ANOVAs on the Open Question, $F(2,22)=15.69, p<.001, \mathrm{y}^{2}$ $=.588$, Reflection of Content, $F(2,22)=26.79, p<.001, \mathrm{y}^{2}=.709$; Reflection of Feeling, $F(2,22)=7.995, p<.002, \mathrm{y}^{2}=.421$, Information, $F(2,22)=22.59, p<.001$, $\mathrm{y}^{2}=.672$, and Interpretation, $F(2,22)=99.97, p<.001, \mathrm{y}^{2}=.901$ were significant. There were no significant differences for the variables Attending, $F(2,22)=1.270, p<$ $.301, \mathrm{n}^{2}=.104 ;$ and Other, $F(2,22)=.967, p<.396, \mathrm{y}^{2}=.081$.

Post hoc analyses for the univariate ANOVA for the variables consisted of conducting pairwise comparisons using Bonferroni tests. These tests revealed that there were significant differences between the Feedback group and No-Feedback group, $p<$ .001. Scores for participants in the Feedback group were higher than those for participants in the No-Feedback group for the variable Interpretation. Scores were higher for participants in the No-Feedback group for the variable Information.

Significant differences were also found between the Feedback group and Reflective-Counseling group, $p<.001$. Scores for participants in the ReflectiveCounseling group were higher than for participants in the Feedback group for the variables Open Question, Reflection of Content, and Reflection of Feeling.

Scores for participants of the Feedback group were higher than for participants of the Reflective-Counseling group for the variable Interpretation. Further, significant differences were found between the Reflective-Counseling group and No-Feedback group, $p<.001$.

Scores for participants of the Reflective-Counseling group were higher than for participants of the No-Feedback group for the variables Open Question, Reflection of Content, and Reflection of Feeling. Scores for the No-Feedback group were higher than 
for the Reflective-Counseling group for the variable Information. No significant differences were found among the three groups on the variables Attending and Other.

\section{Assessor Effects}

This study used 4 assessors. A series of ANOVAs was conducted to see whether there were significant differences in the measures across the therapists. Crosstabulations with chi-square analyses were used to test whether there were significant differences in distribution of clients across the different groups (Feedback, Reflective-Counseling, NoFeedback) by assessor. Results showed that there were no significant differences in the measures or across conditions.

\section{DISCUSSION}

\section{Summary of Findings}

The purpose of this study was first, to extend the current knowledge base on empirical research in the area of assessment feedback. Secondly, this study was conducted to study more clearly the "specific elements" of assessment feedback, to help "minimize nonessential components" (Finn \& Tonsager, 1992, 1997) and to help provide an efficient way to deliver assessment feedback. Specifically, this study aimed to more rigorously test the effects of a key ingredient hypothesized to account for the positive effects of assessment feedback previously found (Allen et al., 2003; Finn \& Tonsager, 1992; Newman \& Greenway, 1997), interpretive information, while ensuring treatment integrity and assessor credibility across the conditions.

With regards to the study's Research Question 1 that asked whether or not there would be better rapport between the investigators and the participants of the Feedback group when compared to the other groups, the present results indicate that providing feedback in the form of interpretive information did have a significant effect on rapport- 
building. However, although a significant difference was found between the Feedback and No-Feedback groups, this was not the case when comparing the Feedback and Reflective-Counseling groups. The results further revealed that participants of the Reflective-Counseling group considered the assessors to be more accepting than participants in the No-Feedback group.

Research Question 1 also asked about potential negative feelings participants might have about the assessment. As found in previous research (Allen et al., 2003; Finn \& Tonsager, 1992), the present results also revealed that, regardless of condition, participants did not have significantly negative feelings about the assessment process.

Research Question 2 examined self-enhancement (self-esteem, self-verification, self-discovery) across the three different groups. Results revealed that although findings were not significant in terms of the two factors of self-esteem, self-liking and selfcompetence, a trend in the data could be found. Specifically, participants in the NoFeedback group had lower scores on the self-competence factor.

In examining self-verification and self-discovery, results of this study revealed significant differences among the three groups (Feedback, Reflective-Counseling, NoFeedback). Specifically, participants in the Feedback groups showed significant increases in self-verification and self-discovery when compared to participants in the ReflectiveCounseling and No-Feedback groups.

Research Question 3 examined symptom decreases as a possible effect of the provision of assessment feedback. Results revealed that the decreases in symptoms found in previous research (Finn \& Tonsager, 1992; Newman \& Greenway, 1997) were not found in this study subsequent to providing assessment feedback as interpretive 
information. However, an overall significant decrease in symptoms across the three groups was found.

Research Question 4 examined the credibility of the assessors across the different group conditions. Consistent with previous research (Allen et al., 2003), no significant differences across groups were found.

\section{Participants' Relationship with Assessor}

The results of this study show that the relationship with the assessor was rated differently across the three groups. Specifically, participants in the Feedback group reported a significantly more positive relationship with the assessors than participants in the No-Feedback group. It can therefore be concluded from this finding that participants in the Feedback group felt a greater sense of rapport with their investigator. This result has been found in past studies (Allen et al., 2003; Finn \& Tonsager, 1992; Newman \& Greenway, 1997). However, the past studies hypothesized that this rapport-building boost was due to the provision of feedback. The present study shows that this assertion is a premature one to make. Because the previous studies (Allen et al., Finn \& Tonsager, 1992; Newman \& Greenway, 1997) had only one control group-an Attention/Information-Only group - it was a logical assumption to make. The addition of another group in this study's design, however, shows that the rapport-building effect does not appear to be due to the provision of feedback only. Rather, it appears that the interaction with the assessor after having participated in the assessment serves to increase rapport between participant and assessor. This finding is further underscored by this study's finding that participants in the Reflective-Counseling group rated the assessors as more accepting. 
Therefore, given that rapport-building was positively affected in both the

Feedback and Reflective-Counseling groups, it can be concluded that rapport-building may be affected by the combined effects of participating in an assessment and interacting with an assessor in a therapeutic session afterwards. Filling out assessment questionnaires at the onset of a therapeutic relationship can thus increase rapport if the assessment is followed up with a therapeutic meeting afterwards. This finding is important in that it sheds some light on the effects that assessment can have on interpersonal variables, such as rapport-building.

\section{Participants' Reactions to Assessment}

Although anecdotal accounts speak favorably of using assessment feedback in private practice (Peterson, 1998), research continues to remain sparse. The studies conducted in the area (e.g., Finn \& Tonsager, 1992) all support the efficacy of assessment feedback while failing to answer satisfactorily what actually accounts for the therapeutic effects. The necessity of more rigorously studying the assessment feedback approach is further compounded by the APA's ethical mandate (ES: 9.10, American Psychological Association, 2002) to provide clients with the results of their psychological testing. But is providing those results to clients actually a therapeutically advantageous move?

The results of this study are important in that they expand the existing research on the putative effects of assessment feedback. This is especially relevant in light of the increasing tendency to use empirically validated assessments at the onset of treatment. Time in therapy is precious and necessarily time-limited. Thus, considering the amount of time that is devoted to conducting valid and reliable assessments, it follows that a therapist would want to use this process therapeutically, if possible. Therefore, it is necessary to test how clients may respond to the assessment process and to receiving the 
results of the assessment. Filling out a multitude of questionnaires can be timeconsuming and energy-draining on part of the client. It is therefore important to examine how clients might view the assessment whether they received the results of their testing or not.

The results of this study revealed that participants did not show any negative tendencies towards the assessment process. Moreover, regardless of whether the participants were (a) given their actual assessment results, (b) had a chance to reflect on the assessment, or (c) simply were provided with information about the assessment process, filling out the questionnaires did not negatively color their experience. This finding is important in that it implicitly encourages the use of assessment batteries. According to this study's findings, it does not appear that clients object to psychological testing, or that filling out lengthy questionnaires has a negative effect on their assessment experience. Having a positive assessment experience with an assessor who not only comes across as accepting, but who also facilitates rapport-building can also make the transition into therapy easier.

The findings of this study discussed so far support the notion that psychological assessment, or, to be more specific, personality assessment, does not leave the assessed person drained and feeling negative about the experience. Moreover, the assessor can use the assessment therapeutically to jump-start the rapport-building process with the client. It does not appear that to make this therapeutic gain, the actual results of the testing have to be divulged, but rather allowing the client to reflect on the assessment itself without receiving actual results can also further rapport-building. 


\section{Effects of Assessment Feedback on Self-Enhancement Processes}

Previous studies have shown that participants who received assessment feedback evidence a greater sense of self-enhancement (Allen et al., 2003; Finn \& Tonsager, 1992; Newman \& Greenway, 1997). Self-enhancement was assessed by several factors, selfesteem-measured as a two-factor construct, self-liking and self-competence-self verification, and self-discovery. This study aimed to further investigate whether these findings would persist with a design more rigorously focused on looking at the actual effects of assessment feedback defined as interpretive information. This study's results lend partial support for this self-enhancement hypothesis.

In terms of self-esteem, the results showed no significant increases as a result of the assessment or as a result of the conditions. There were slight mean increases in both the Feedback and Reflective-Counseling condition in both factors (self-liking and selfcompetence). These increases, however, were not significant. Interestingly, scores declined from pre to post, across both factors in the No-Feedback group. In terms of the self-competence factor, this decrease was statistically significant.

These findings are interesting in that they shed more light on the effects the assessment process can have on intrapersonal processes. According to this study's findings, receiving interpretive information in the form of assessment feedback from a personality inventory, does not in and of itself increase one's self-esteem; nor does being able to reflect on the test-experience, or simply taking an assessment affect any positive change in self-esteem. Moreover, in the latter case, it may even lead to a decrease in selfesteem, as could be seen in this study's No-Feedback group.

Previous studies have, however, found significant increases in self-esteem (Allen et al., 2003; Finn \& Tonsager, 1992; Newman \& Greenway, 1997). This could be due to 
several factors. First, as mentioned above, both the Finn and Tonsager (1992) and Newman and Greenway (1997) studies used Finn's (1996) approach to providing clients with assessment feedback. This approach is essentially a conglomerate of several therapeutic elements (information, interpretive information, reflection, goal-setting). This study's finding showed that the positive increases in self-esteem cannot be attributed to the isolated element, interpretive information. This study's findings therefore imply that it may rather be the combined effects of these elements that bring about positive changes.

Furthermore, providing participants with objective information about their personality assessments requires divulging not only positive information, as was the case in the Allen et al. (2003) study, but also discussing problem areas. The Allen et al. (2003) study used a non-clinical sample that received information from a normal-variant personality inventory, the Millon Index of Personality Styles (MIPS). Thus, the information received did not include any clinical or problem area-oriented information. In light of this present study's findings, it appears that the interpretive information component of assessment feedback from a clinical inventory is not enough to bring about positive changes in self-esteem. The effects of a combination of therapeutic techniques might better account for the results from previous studies (Finn \& Tonsager, 1992; Newman \& Greenway, 1997).

In terms of self-verification, the results of the current study show that there were significant differences among the three groups (Feedback, Reflective-Counseling, NoFeedback). Consistent with results from previous studies (Allen et al., 2003; Finn \& Tonsager, 1992; Newman \& Greenway, 1997), participants who received assessment feedback about their personality inventories experienced an increased sense of self- 
verification. The results show that the Feedback group participants' increase in selfverification was significantly higher than in the two other groups.

Equally significant were the findings in terms of self-discovery. Participants in the Feedback group showed a significantly higher sense of self-discovery along with an overall higher degree of satisfaction about the assessment. Again, the results show that the differences between all three groups were such that the Feedback group's results were significantly higher than the other two groups (Reflective-Counseling, No-Feedback).

\section{Effects of Assessment Feedback on Symptoms}

As done in previous studies in the area of assessment feedback (Finn \& Tonsager, 1992; Newman \& Greenway, 1997), the present study also asked whether receiving interpretive information from a personality inventory would positively affect participants' subjective level of symptomatic distress. Previous studies (Finn \& Tonsager, 1992; Newman \& Greenway, 1997) found significant decreases in symptomatic distress as a result of being provided with assessment feedback. Results of the present study also showed a significant decrease in symptoms, however, this decrease was across all three groups as a function of time. No significant effect could be found as a function of group.

Thus, participants reported a decrease in symptoms after having met with the assessor individually after the assessment, regardless of group. These results are interesting in that they emphasize the results in terms of participants' feelings about the assessment. As discussed previously, regardless of group participants reported not having any negative feelings about the assessment. This finding is supported by the decrease in symptomatic distress. Thus, not only did the assessment part not bring about any negative feelings in the participants, it also led to a decrease in symptoms. 
Therefore, the findings from previous studies (Finn \& Tonsager, 1992; Newman \& Greenway, 1997) were not consistent with those observed here. The findings of this present study. It could be that taking a test that asks questions which are high in face validity, such as the MCMI-III, leads to a decreasing trend in symptoms. However, this remains an empirical question to be answered by future research. Comparing the effects that a particular test might have over another could shed light on this question. Thus, a future research design might use the MMPI-2 as a stimulus and compare it to another personality inventory, such as the MCMI-III. The results of this study in terms of symptomatic distress thus imply that providing interpretive information as assessment feedback alone does not bring about clinically significant changes in the client's level of distress, but rather symptomatic decrease may be effected as a function of taking the test.

\section{Theoretical Implications of Findings}

Findings from previous research in the area of assessment feedback (Finn \& Tonsager, 1992; Newman \& Greenway, 1997) could be theoretically tied to two perspectives: Swann's self-verification theory (e.g., McNulty \& Swann, 1991) and Festinger's cognitive dissonance theory (Festinger, 1957). Specifically, positive increases in self-enhancement and rapport-building can be explained by Swann's self-verification theory (e.g., McNulty \& Swann, 1991). Clients' symptom improvement can be explained by Festinger's cognitive dissonance theory (1957).

According to McNulty and Swann (1991), people seek feedback about themselves to make their lives more predictable and controllable. Further, receiving feedback about oneself can increase a sense of being understood, while confirming one's self-image. This theoretical explanation has served to elucidate the positive effects found in previous studies using assessment feedback (Allen et al., 2003; Finn \& Tonsager, 1992; Newman 
\& Greenway, 1997). This phenomenon has been credited for increases in terms of rapport-building between client and assessor, self-verification, and self-discovery. Swann's self-verification theory, however, can only be used implicitly to explain increases in self-esteem following assessment feedback. Moreover, Giesler et al. (1996), found that although people seek out feedback about themselves, and may even seek out negative feedback about themselves, this did not result in changes in self-esteem. However, Swann's self-verification theory was regarded as a potential explanation for the positive results of assessment feedback on increases in self-esteem by previous studies (Finn \& Tonsager, 1992; Newman \& Greenway, 1997). Results of the present study, however, support more strongly the assertion that people strive to maintain feelings of self-worth, self-liking, and self-competence (Bosson \& Swann, 1999). Participants across the three groups in the present study did indeed maintain their feelings of self-liking and self-competence when provided with assessment feedback. Further research is needed to examine the role that specific elements of assessment feedback can have on increases in self-esteem.

This study's results suggest that receiving assessment feedback in the form of informative information about a personality inventory positively affects self-enhancement processes by increasing self-discovery and self-verification. In other words, assessment feedback in the form of interpretive information can increase a sense of having one's beliefs about oneself confirmed and create a sense of having learned new aspects about oneself. Although the tendency to seek out feedback about oneself appears to exist, it does not necessarily imply that receiving such feedback will make one feel more selfcompetent or increase one's sense of self-liking. 
This study's results also support Swann's self-verification theory in that the effects on self-discovery and self-verification were independent of the actual content (positive/negative) of the feedback given. As mentioned above, the interpretive information was gathered from a clinical test, which outlined strengths as well as weaknesses and clinically noteworthy areas in the participants' level of functioning. Thus, a person with a depressive personality style, for example, would receive interpretive information about how such a style impacts his or her daily functioning and interpersonal relationships. Therefore, assessment feedback as interpretive information impacts intrapersonal variables by increasing self-enhancement in terms of selfverification and self-discovery.

The present findings suggest that the effects of assessment feedback in the form of interpretive information on decreasing clients' symptoms need further investigation. Festinger (1957) hypothesized that a feeling of cognitive dissonance comes about when clients feel inconsistency within themselves. Such a feeling of inconsistency can be evidenced by symptom distress. Results of this study were not consistent with previous findings (e.g., Finn \& Tonsager, 1992). Isolating specific elements of assessment feedback that have the potential of further affecting symptom decrease should therefore be the focus of future research. Festinger's theory of cognitive dissonance (1957) and how it applies to assessment feedback could be tested further in a research design that more closely looks at factors that motivate and engage clients for treatment.

\section{Assessor Credibility}

This study aimed to test whether the therapist would be perceived differently based on whether they received assessment feedback, reflective counseling or nofeedback. In other words, were participants evaluating the therapist differently based on 
the content of their individual meeting with the therapist? One of the research questions of this study examined how participants would evaluate the assessor (e.g., less/more competent, less/more friendly, or less/more expert). The Allen et al. (2003) study used this manipulation check as well and the present study's results were consistent with the Allen et al. study. Additionally, there were no therapist effects found in this study, implying that positive results are not dependent on a particular assessor.

These findings in terms of assessor evaluation and effects are significant in that they provide further support for the above-mentioned assertion that assessment does not negatively affect a client's assessment experience. Specifically, not only were there no significant group differences in how the participants evaluated the assessors, assessors were rated positively across the three conditions.

In sum, the merits of providing clients with assessment feedback in the form of interpretive information appear to affect interpersonal variables (rapport-building), as well as intrapersonal variables (self-discovery and self-verification). These variables can be used to increase motivation for treatment and guide the client from the assessment part of therapy to the actual intervention sessions by furthering the therapeutic relationship between the assessor and client.

Thus, the question whether it is the actual information that is being provided during the course of assessment feedback that brings about positive results must necessarily be answered in light of this study's results with a "Yes and No." Yesreceiving interpretive information does appear to positively impact rapport-building, selfverification, and self-discovery. No-providing interpretive information does not lead to increases in self-esteem or decreases in symptoms. More specifically, with the help of an assessment inventory, the assessor can function as the one guiding the client to increased 
self-verification and self-discovery, thus positively affecting and furthering rapportbuilding in the therapeutic relationship. However, in terms of internal client variables, such as self-esteem and symptoms, it appears that providing interpretive information is not enough to bring about significant change. It therefore follows that the positive results obtained in previous studies in terms of these intrapersonal client variables (e.g., Finn \& Tonsager, 1992; Newman \& Greenway, 1997) may be due to the combined effects of the multitude of therapeutic elements used.

\section{Limitations of Findings}

A discussion of this study's limitations is in order. This study sought to further elucidate the effects of assessment feedback by adding another group to the design and by more rigorously testing the effect of the actual interpretive information provided during the assessment feedback session. This study did not include a group equivalent to the assessment feedback groups used in previous studies (Finn \& Tonsager, 1992; Newman \& Greenway, 1997). Those studies used assessment feedback based on an approach devised by Finn (1996). Future research might want to include such a group again and test it against another counseling technique.

Further, future research may want to use a larger sample size to explore the effects of providing assessment feedback on perceived levels of self-competence. This study found a trend toward a decrease in self-competence in participants who did not receive any feedback. Investigating this trend in a future study would shed further light on the intrapersonal processes following assessments.

Previous studies (e.g., Finn \& Tonsager, 1992) used a college student sample. This present study's sample was also comprised of participants from the university community. Therefore, the sample of this study is comparable to the ones used in 
previous research. However, future studies would benefit from testing the effects of assessment feedback using a clinical sample (outpatient and inpatient).

Also, this study could not, due to insufficient power, investigate the effects that receiving interpretive information had on participants based on their actual personality styles. Further research could examine how participants accept feedback differently based on their personality styles, level of pathology, etc. Additionally, Festinger's theory of cognitive dissonance (1957), as it applies to assessment feedback, could be tested further in a research design that more closely looks at factors that motivate clients for treatment.

\section{Future Directions}

In sum, the implications of the findings of this study for practitioners are worth mentioning. It appears that overall, providing clients with the results of their assessment results has positive effects. Providing clients with interpretive information from a personality inventory can lead to an increase in rapport-building, a greater sense of selfverification, and aid the process of self-discovery. Furthermore, although a more involved assessment feedback model may be necessary to bring about more clinically significant changes, using assessments as a starting point in therapy may be beneficial to clients. Choosing to provide clients with interpretive information instead of using a more elaborate model (e.g., Finn, 1996), also has pragmatic implications. Providing interpretive information assessment feedback is less training-intensive and can thus be incorporated more readily into an assessment procedure without being too timeconsuming. Adding interpretive information assessment feedback to the assessment process can change the meaning of the assessment. Assessments can therefore serve not only as a tool for providing the assessor/therapist with valid and reliable information about the client, but also as a platform from which to launch the treatment process. The 
above- described effect of assessment feedback can thus be used to strengthen the therapeutic relationship and motivate clients to continue a journey of self-discovery alongside the therapist.

Furthermore, therapists need not shy away from presenting clients with the results of their assessments fearing that it may negatively affect the therapeutic relationship or might even harm the client. Such fears are not supported by this study's results. Thus, providing clients with interpretive information from a personality assessment can be used as a starting point in therapy. 
Table 1.

Sociodemographic Characteristics of Participants in Feedback, ReflectiveCounseling and No-Feedback Groups $(N=89)$

\begin{tabular}{|c|c|c|c|c|c|c|}
\hline $\begin{array}{l}\text { Group } \\
\text { Variable }\end{array}$ & \multicolumn{2}{|c|}{ Feedback } & \multicolumn{2}{|c|}{$\begin{array}{l}\text { Reflective- } \\
\text { Counseling }\end{array}$} & $(n=27)$ & back \\
\hline \multicolumn{7}{|l|}{ Gender } \\
\hline Male & 10 & 34.5 & 7 & 21.2 & 10 & 37.0 \\
\hline Female & 19 & 65.5 & 26 & 78.8 & 17 & 63.0 \\
\hline \multicolumn{7}{|l|}{ Ethnicity } \\
\hline White & 6 & 20.7 & 10 & 30.3 & 4 & 14.8 \\
\hline Black & 1 & 3.4 & 3 & 9.1 & & \\
\hline Haitian & 2 & 6.9 & & & 1 & 3.7 \\
\hline Jamaican & & & 1 & 3.0 & 1 & 3.7 \\
\hline $\begin{array}{l}\text { Hispanic/ } \\
\text { Latino }\end{array}$ & 18 & 62.1 & 18 & 54.6 & 20 & 74.1 \\
\hline $\begin{array}{l}\text { Asian/ } \\
\text { Pacific } \\
\text { Islander }\end{array}$ & 1 & 3.4 & 1 & 3.0 & 1 & 3.7 \\
\hline Other & 1 & 3.4 & & & & \\
\hline
\end{tabular}




\section{Table 2.}

Sociodemographic Characteristics of Participants in Feedback, Reflective Counseling and No-Feedback Groups (Age)

\begin{tabular}{lllllll}
\hline Group & Feedback & & $\begin{array}{l}\text { Reflective- } \\
\text { Counseling } \\
(\mathrm{n}=33)\end{array}$ & \multicolumn{2}{l}{ No-Feedback } \\
Variable & Mean & SD & Mean & SD & Mean & SD \\
\hline Age (years) & 23.8 & 4.9 & 24.9 & 7.6 & 24.3 & 6.3 \\
\hline
\end{tabular}




\section{Table 3.}

Means and Standard Deviations on Rapport-Building, and Self-Enhancement and Symptomatology Measures by Group

\begin{tabular}{|c|c|c|c|c|c|c|}
\hline \multirow[b]{2}{*}{ Measure } & \multicolumn{2}{|c|}{$\begin{array}{l}\text { Feedback } \\
(n=29)\end{array}$} & \multicolumn{2}{|c|}{$\begin{array}{l}\text { Reflective- } \\
\text { Counseling } \\
(\mathrm{n}=33)\end{array}$} & \multicolumn{2}{|c|}{$\begin{array}{l}\text { No-Feedback } \\
(n=27)\end{array}$} \\
\hline & Mean & SD & Mean & SD & Mean & SD \\
\hline \multirow{2}{*}{\multicolumn{7}{|c|}{ Rapport-Related Measures }} \\
\hline & & & & & & \\
\hline NFA & 1.49 & .42 & 1.61 & .49 & 1.53 & .53 \\
\hline PRI & $3.96 \mathrm{a}$ & .49 & $3.79 \mathrm{a}$ & .43 & $3.55 b$ & .61 \\
\hline GS & $3.35 \mathrm{a}$ & .40 & $2.91 \mathrm{~b}$ & .49 & $2.59 \mathrm{c}$ & .61 \\
\hline \multicolumn{7}{|l|}{ CPM } \\
\hline Acceptance & $31.24 \mathrm{a}$ & 3.20 & $31.70 \mathrm{a}$ & 3.07 & $29.19 \mathrm{t}$ & 3.64 \\
\hline
\end{tabular}

Self-Esteem

Self-Enhancement Measures

SLCS-R

$\begin{array}{llllll}\text { Self-Liking pre } 28.24 & 7.21 & 30.48 & 6.30 & 31.07 & 6.41 \\ \text { Self-Liking post 28.44 } & 6.83 & 31.27 & 7.43 & 30.40 & 7.08 \\ \text { Self-Comp. pre 28.00 } & 4.94 & 29.27 & 4.91 & 30.56 & 3.92 \\ \text { Self-Comp. post 28.48 } & 4.97 & 28.73 & 4.38 & 29.11 & 4.22\end{array}$

Self-Verification

$\begin{array}{lllllll}\text { PAM } & 3.85 \mathrm{a} & .56 & 3.21 \mathrm{~b} & .71 & 2.84 \mathrm{~b} & .79\end{array}$

Self-Discovery

\begin{tabular}{lllllll} 
NSA & $3.73 \mathrm{a}$ & .55 & $3.12 \mathrm{~b}$ & .81 & $2.51 \mathrm{c}$ & .88 \\
\hline \multicolumn{5}{c}{ Symptomatology Measure }
\end{tabular}

BSI

\begin{tabular}{lcccccc} 
BSI pre & 60.66 & 7.20 & 59.15 & 7.39 & 59.27 & 7.78 \\
BSI post & 56.10 & 9.34 & 54.36 & 9.19 & 55.12 & 9.37 \\
\hline \multicolumn{7}{c}{ Assessor Credibility }
\end{tabular}

\begin{tabular}{lllllll} 
CPM total score & 75.14 & 6.66 & 72.67 & 7.22 & 71.03 & 8.64 \\
\hline
\end{tabular}

Note. AQ-2 = Assessment Questionnaire 2; NFA = Negative Feelings about Assessment; PRI = Positive Relationship with Investigator; $G S=$ Global Score; $P A M=$ Positive Accurate Mirroring; NAS = New Self Awareness; $\mathrm{CPM}=$ Counselor Perception Measure: $\mathrm{BSI}=$ Brief Symptom Inventory.

Vote. Means in a row with differing subscripts are significantly different using Bonferroni tests. 


\section{Table 4a.}

Multivariate and Univariate Analyses of Variance for Rapport-Building Measures (Positive Relationship with Investigator; Negative Feelings about Assessment)

Univariate

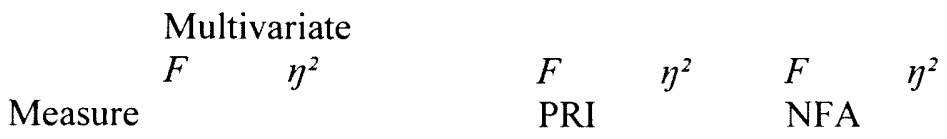

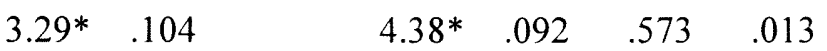

$* \mathrm{p}<.05 * * \mathrm{p}<.01$

Note. $\mathrm{NFA}=$ Negative Feelings about Assessment; PRI $=$ Positive Relationship with Investigator; Acceptance $=$ Acceptance subscale of Counselor Perception Measure.

\section{Table 4b.}

Univariate Analysis of Variance for Rapport-Building Measures (Acceptance)

Variable

$d f$

$F$

$\eta^{2}$

Acceptance

2

4.16*

.088

$* p<.05$ 


\section{Table 5.}

Multivariate and Univariate Analyses of Variance for Self-Enhancement Measures (Self-Verification \& Self-Discovery)

Univariate

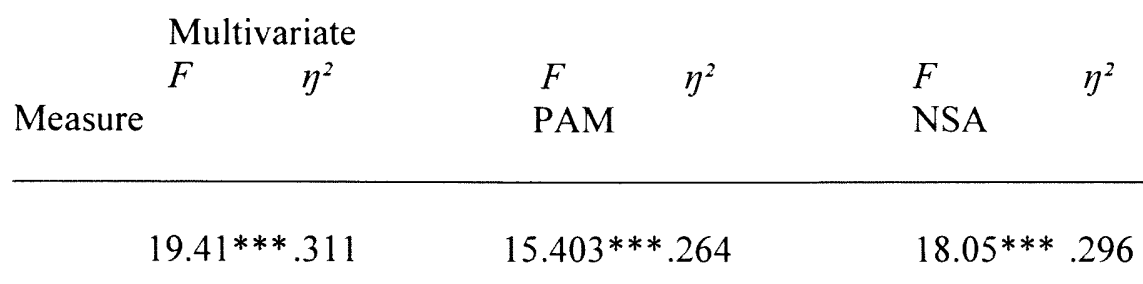

$* \mathrm{p}<.05 * * \mathrm{p}<.01 * * * \mathrm{p}<.001$

Note. $\quad$ PAM $=$ Positive Accurate Mirroring; NAS $=$ New Self Awareness. 
Table 6.

Multivariate and Univariate Analyses of Variance for Repeated Self-Enhancement Measures (Self-Esteem)

\section{Univariate}

Multivariate

$\begin{array}{llllll}F & \eta^{2} & F & \eta^{2} & F & \eta^{2}\end{array}$

Variable

Self-Liking Self-Competence

\begin{tabular}{lccccccc}
\hline Time & 1.38 & .032 & .085 & .772 & 2.37 & .027 \\
Group & 1.44 & .032 & 1.37 & .031 & .947 & .022 \\
Time x Condition & 2.84 & .062 & 1.26 & .029 & 2.77 & .060 \\
\hline
\end{tabular}

$* \mathrm{p}<.05 * * \mathrm{p}<.01 * * * \mathrm{p}<.001$ 


\section{Table 7.}

Univariate Analysis of Variance for Repeated Symptomatology Measure (BSI)

\begin{tabular}{lccc} 
Variable & $d f$ & \multicolumn{1}{l}{$F$} & $\eta^{2}$ \\
\hline Time & 1 & $41.22^{* * *}$ & .327 \\
Group & 2 & .353 & .008 \\
Time x Condition & 2 & .069 & .002
\end{tabular}

$* \mathrm{p}<.05^{* *} \mathrm{p}<.01 * * * \mathrm{p}<.001$ 
Table 8.

Means and Standard Deviations on Treatment Integrity Variables

\begin{tabular}{|c|c|c|c|c|c|c|}
\hline \multirow[b]{2}{*}{ Variable } & \multicolumn{2}{|c|}{ Feedback } & \multicolumn{2}{|c|}{$\begin{array}{l}\text { Reflective- } \\
\text { Counseling }\end{array}$} & \multicolumn{2}{|c|}{ No-Feedback } \\
\hline & Mean & SD & Mean & SD & Mean & SD \\
\hline Attending & 2.50 & 1.98 & 2.92 & 3.92 & .71 & .76 \\
\hline Open Question & 2.33 & 1.75 & 10.67 & 5.16 & 1.71 & 1.89 \\
\hline \multicolumn{7}{|l|}{ Reflection of } \\
\hline Content & $.67 \mathrm{a}$ & 1.03 & $9.42 \mathrm{~b}$ & 4.25 & $.29 \mathrm{c}$ & .49 \\
\hline \multicolumn{7}{|l|}{ Reflection of } \\
\hline Feeling & $.33 \mathrm{a}$ & .52 & $12.25 \mathrm{~b}$ & 10.61 & $.14 \mathrm{c}$ & .38 \\
\hline Information & $3.83 \mathrm{a}$ & 4.07 & $.75 b$ & .97 & $14.29 \mathrm{c}$ & 7.18 \\
\hline Interpretation & $20.17 \mathrm{a}$ & 5.35 & $1.00 \mathrm{~b}$ & 1.86 & $.43 b$ & 1.13 \\
\hline Other & 1.17 & .753 & 1.08 & .79 & 1.71 & 1.38 \\
\hline
\end{tabular}

Note. Means in a row with differing subscripts are significantly different using Bonferroni tests. 
Table 9.

Multivariate and Univariate Analyses of Variance for Assessor Credibility and Treatment Integrity

\begin{tabular}{lcc}
\multicolumn{2}{c}{ (Multivariate) Univariate } \\
Measure & $F$ & $\eta^{2}$ \\
& & \\
CPM & 2.13 & .047 \\
\hline Treatment Integrity & $(28.77$ & $.022)$ \\
Open Question & $15.69 * * *$ & .588 \\
Reflection of Content & $26.79 * * *$ & .709 \\
Reflection of Feeling & $7.99 * *$ & .421 \\
Information & $22.59 * * *$ & .672 \\
Interpretation & $99.97 * * *$ & .901 \\
Attending & 1.270 & .104 \\
Other & .967 & .081 \\
\hline
\end{tabular}

$* \mathrm{p}<.05 * * \mathrm{p}<.01 * * * \mathrm{p}<.001$ 
Allen, A., Montgomery, M., Tubman, J., Frazier, L., \& Escovar, L. (2003). The effects of assessment feedback on rapport-building and self-enhancement processes. Journal of Mental Health Counseling, 25, 165-181.

American Psychiatric Association. (1994). Diagnostic and statistical manual of mental disorders $\left(4^{\text {th }}\right.$ ed.). Washington, DC: American Psychiatric Association.

American Psychological Association. (2002). Ethical principles of psychologists and code of conduct. Washington, DC: American Psychological Association.

Arkowitz, H. (1992). Integrative theories of therapy. In D. Freedheim (Ed.), History of Psychotherapy (pp. 261-303). Washington, D.C.: American Psychological Association.

Atkinson, D. R. \& Wampold, B. E. (1982). A comparison of the Counselor Rating Form and the Counselor Effectiveness Rating Scale. Counselor Education and Supervision, 22, 25-36.

Aubrey, L. (1998). Motivational interviewing with adolescents presenting for outpatient substance abuse treatment. Dissertation Abstracts International, 59 (3-B), 1357.

Baker, L. (1987). Families and Illness. In M. Crouch \& L. Roberts (Eds.), The family in medical practice (pp. 97-111). Berlin: Springer Verlag.

Baucom, D. \& Epstein, N. (1990). Cognitive-behavioral marital therapy. (pp. 242-246). New York: Brunner/Mazel.

Bosson, J. K., \& Swann, W. B., Jr. (1999). Self-liking, self-competence, and the quest for self-verification. Personality \& Social Psychology Bulletin Oct 1999, 25 (10), 1230-1241.

Butcher, J. N., Dahlstrom, W., Graham, J., Tellegen, A., \& Kaemmer, B. (1989). Minnesota Multiphasic Personality Inventory-2 (MMPI-2): Manual for administration and scoring. Minneapolis, MN: University of Minnesota Press.

Butcher, J. N. (1990). The MMPI-2 in psychological treatment. (pp. 146-164). New York, NY: Oxford University Press.

Choca, J., \& Van Denburg, E. (1996). Interpretive guide to the Millon Clinical Multiaxial Inventory $\left(2^{\text {nd }}\right.$ ed.) Washington, DC: American Psychological Association.

Dana, R. H. (1982). A human science model for personality assessment with projective techniques. Springfield, IL: Thomas. 
Derogatis, L.R. (1983). SCL-9—R: Administration, scoring, and procedures manual-II for the R(evised) Version. Towson, MD: Clinical Psychometric Research.

Derogatis, L.R. (1993). BSI: Brief Symptom Inventory Administration, scoring, and procedures manual. Minneapolis, MN: NCS Pearson.

DiClemente, C., Bellino, L., \& Neavins, T. (1999). Motivation for change and alcoholism treatment. Alcohol Research and Health, 23, 86-92.

Dunn, C., Deroo, L., \& Rivera, F.P. (2001). The use of brief interventions adapted from motivational interviewing across behavioral domains. Addiction, 96, 1725-1742.

Festinger, L. (1957). A theory of cognitive dissonance. Stanford, CA: Stanford University Press.

Finn, S., \& Tonsager, M. (1992). Therapeutic effects of providing MMPI-2 test feedback to college students awaiting therapy. Psychological Assessment, 4, (3), 278-287.

Finn, S., \& Tonsager, M. (1995). The Assessment Questionnaire-2 (AQ-2): A measure of clients' experiences with psychological assessment. Unpublished manuscript. Austin, TX: Center for Therapeutic Assessment.

Finn, S. (1996). Using the MMPI-2 as a therapeutic intervention. Minneapolis, MN: University of Minnesota Press.

Finn, S., \& Tonsager, M. (1997). Information-gathering and therapeutic models of assessment: complementary paradigms. Psychological Assessment, 9 (4), $374-$ 385 .

Forer, B.R. (1949). The fallacy of personal validation: A classroom demonstration of gullibility. Journal of Abnormal and Social Psychology, 44, 118-123.

Furnham, A. \& Schofield, S. (1987). Accepting personality test feedback: A review of the Barnum Effect. Current Psychological Research and Reviews, Summer 1987, 6 (2), 162-178.

Giesler, R.B., Josephs, R.A., Swann W.B., Jr. (1996). Self-verification in clinical depression: The desire for negative evaluation. Journal of Abnormal Psychology, August 1996, 105(3), 358-368.

Hickman, M. (1997). The effects of personal feedback on alcohol intake in dually diagnosed clients: An empirical study of William R. Miller's motivational enhancement therapy. Dissertation Abstracts International 60 (1-B), 0367.

Hill, C. E. \& O’Brien, K. M. (1999). Helping skills. Facilitating exploration, insight, and action. Washington, DC: American Psychological Association. 
Meehl, P.E. (1956). Wanted-a good cookbook. American Psychologist, 11, 262-272.

McConnaughy, E.N., Prochaska, J.O., \& Velicer, W.F. (1983). Stages of change in psychotherapy: Measurement and sample profiles. Psychotherapy: Theory, Research and Practice, 20, 368-375.

McLennan, J. (1990). Clients' perceptions of counsellors: A brief measure for use in counselling research, evaluation, and training. Australian Psychologist, 25, 133146.

McNulty, S.E., \& Swann, W.B., Jr. (1991). Psychotherapy, self-concept change, and selfverification. In R.C. Curtis (Ed.) The relational self: Theoretical convergence of psychoanalysis and social psychology (pp. 213-237). New York, NY: Guilford.

Miller, G. (1997). The Substance Abuse Subtle Screening Inventory (SASSI). Bloomington, IN: SASSI Institute.

Miller, W.R., Sovereign, R.G., \& Krege, B. (1988). Motivational interviewing with problem drinkers: II. The Drinker's Check-up as a preventive intervention. Behavioural Psychotherapy, 16, 251-268.

Miller, W. R., \& Rollnick, S. (1991). Motivational Interviewing. New York, NY: Guilford Press.

Miller, W. R. (1995). Increasing motivation for change. In R. K. Hester \& W. R. Miller (Eds.), Handbook of Alcoholism Treatment Approaches. Effective Alternatives ( $2^{\text {nd }}$ ed.), (pp. 1-104). Boston, Mass: Allyn and Bacon.

Miller, W.R., Zweben, A., DiClemente, C.C., \& Rychtarik, R.G. (1995). Motivational enhancement therapy (MET) manual. (Vol. 2) Project MATCH Monograph Series. Rockville, MD: National Institute on Alcohol Abuse and Alcoholism.

Miller, W. R. (1995). Increasing motivation for change. In R. K. Hester, \& W. R. Miller (Eds.), Handbook of alcoholism treatment approaches, $2^{\text {nd }}$ ed. Boston, MA: Allyn and Bacon.

Millon, T., \& Davis, R.D. (1996). Disorders of personality. DSM-IV and beyond. $\left(2^{\text {nd }}\right.$ ed.). New York, NY: Wiley.

Millon, T., Millon, C., \& Davis, R.D. (1997). Millon Clinical Multiaxial Inventory manual III. Minneapolis, MN: NCS Pearson.

Millon, T. \& Davis, R. D. (1997). The place of assessment in clinical science. In T. Millon (Ed.), The Millon inventories (pp. 3-23). New York, NY: Guilford.

Millon, T. \& Davis, R.D. (2000). Personality Disorders in Modern Life. New York, NY: Wiley. 
Millon, T., Weiss, L., Millon, C., \& Davis, R.D. (1994). MIPS: Millon Index of Personality Styles manual. San Antonio: Psychological Corporation.

Newman, M. \& Greenway, P. (1997). Therapeutic effects of providing MMPI-2 test feedback to clients at a university counseling service: A collaborative approach. Psychological Assessment, 9, (2), 122-131.

Olejnik, S., Li, J., Supattathum, S., \& Huberty, C. (1997). Multiple testing and statistical power with modified Bonferroni procedures. Journal of Educational \& Behavioral Statistics, 22, 389-406.

Peterson, S. A. (1998). On the practice of feedback provision in objective personality assessment: An inquiry into the state of the art in our science. Dissertation Abstracts International 59 (7-B), 0367.

Prochaska, J.O. \& DiClemente, C. C. (1994). The transtheoretical approach. Crossing traditional boundaries of therapy. Malabar, FL: Krieger Publishing Co.

Quirk, M., Strohsahl, K., Kreilkamp, T., \& Erdberg, P. (1995). Personality feedback consultation in a managed mental health care practice. Professional Psychology: Research and Practice, 26, (1), 27-32.

Retzlaff, P. (1997). The MCMI as a treatment planning tool. In T. Millon (Ed.), The Millon inventories (pp. 217-245). New York, NY: Guilford.

Rozensky, R., Sweet, J., \& Tovian, S. (1997). Psychological assessment in medical settings. (pp. 26-28). New York, NY: Plenum Press.

Sample, S., \& Kadden, R. (2001). Motivational enhancement therapy and cognitive behavioral therapy for adolescent cannabis users: 5 sessions. Rockville, MD: U.S. Department of Health and Human Services.

Strack, S. (1999). Essentials of Millon Inventories assessment. New York, NY: Wiley.

Sundberg, N.D. (1955). The acceptability of "fake" versus "bona fide" personality test interpretations. Journal of Abnormal and Social Psychology, 50, 145-147.

Tafarodi, R. W. \& Swann, W. B. (1995). Self-liking and self-competence as dimensions of global self-esteem: initial validation of a measure. Journal of Personality Assessment, 65, 322-342.

Tafarodi, R. W. \& Swann, W. B. (2001). Two-dimensional self-esteem: theory and measurement. Personality and Individual Differences, 31, 653-673

Truitt, J. (1999, October). Assessment in Couples Therapy. Workshop presented at the Sixth Annual Millon Clinical Inventories Conference, New Orleans, LA. 
Wills, F. (1997). Cognitive counselling: A down-to-earth and accessible therapy. In C. Sills (Ed.), Contracts in counselling (pp. 51-65). Thousand Oaks, CA: Sage.

Worthington, E., McCullough, M., Shortz, J., Mindes, E., Sandage, S. \& Chartrand, J. (1995). Can couples assessment and feedback improve relationships? Assessment as a brief relationship enrichment procedure. Journal of Consulting Psychology, $42(4), 466-475$. 
APPENDICES 
Appendix A 
One of the characteristics of the MCMI-III is that various personality types and clinical syndromes are believed to be related to one another (Schizoid-Avoidant).

Therefore, some items are shared across the test. Millon identified the most important characteristics of a scale by assigning a weight of 2 to these and giving a weight of one to the less definitive items (Millon, et al., 1997).

Items are given a weight of 2 only once, but may be scored 1 for one or more additional scales. This means that various traits and symptoms can be central to only one personality or syndrome, but may overlap with other related personalities or syndromes. The result of this item overlap is that there are moderately high scale intercorrelations (ranging from -. 80 to +.85 ) (Millon, et al., 1997).

Millon chose Base Rate (BR) scores over $t$-scores. $T$-scores were considered inappropriate because they assume an underlying normal population distribution. The MCMI was validated using a clinical sample. The BR scores reflect the diagnoses of the individuals who make up the sample (Millon, et al., 1997).

Psychometric characteristics. A Baserate (BR) of 60 was set as the median raw score obtained by all patients. BR scores of 75 indicate that criteria for a particular disorder are met. Scores of 75 to 84 indicate that there are clinically significant personality traits. Scores of 85 and above suggest a disorder. For the clinical syndrome scales, BR scores of 75 to 84 indicate the presence of a syndrome, and BR scores of 85 and above indicate the prominence of a syndrome. Raw scores for all scales except for the Disclosure scale (Scale X) are computed by adding up the number of items endorsed for the scales, with the proper weights (Millon, et al., 1997). 
Reliability. The alpha coefficients range from .66 for Scale 7 to .90 for Scale CC. Twenty out of 26 scales have alpha coefficients which surpass .80 . The test-retest reliability correlations, taken from two test administrations, were between 5 and 14 days apart. The correlations range form .82 for Scale $\mathrm{Z}$ to .96 for Scale $\mathrm{H}$ with a median stability coefficient of .91 (Millon, et al., 1997).

Validity. Correlations between the MCMI-III and collateral testing instruments were computed from the BR scores of the MCMI-III and scores from collateral instruments. These collateral instruments were the Beck Depression Inventory (BDI), General Behavior Inventory (GBI), Michigan Alcoholism Screening Test (MAST), Impact of Events Scale (IOES), State-Trait Anxiety Inventory (STAI), Symptom Checklist-90-Revised (SCL-90-R), and the MMPI-2. Relatively high correlations, Major Depression (.74) and Dysthymia (.71), were found between the BDI and a number of MCMI-III scales except for the Histrionic Scale (-. 49), Narcissistic Scale (-. 40), and Compulsive Scale (-. 30). High correlations were also found with the Depressive (.56), Borderline (.56), Self-Defeating (.53), and Schizoid scales (.53). Less strong relationships were established between the Aggressive (.22) and Antisocial (.20) personality disorders scales.

Scoring of the MCMI-III. The MCMI-III can be scored using several techniques. The test can be computer scored-computer generated profiles are available. The MCMIIII can be handscored using a scoring stencil, which takes approximately 45 minutes. Other techniques are telescoring, mail-in answer sheets, or software for personal computers (Strack, 1999).

Raw scores (except for those of the Disclosure scale) are computed by adding the endorsed items for each scale and giving them the appropriate weight ( 1 or 2$)$. The 
Disclosure score is a combination of scores computed from the raw scores of the 11 personality scales. It is calculated as follows:

$$
\text { Disclosure }=\text { Schizoid }+ \text { Avoidant }+ \text { Depressive }+ \text { Dependent }+ \text { Histrionic }+
$$

(Narcissistic x .67) + Antisocial + Aggressive + Compulsive + Passive-Aggressive + Self-Defeating.

All raw scores with the exception of the validity scores are transformed into BR scores using tables provided by the MCMI-III test manual (Millon, et al., 1997). The BR scores obtained then undergo 4 possible corrections-Level of Disclosure, AnxietyDepression, Recent Inpatient Admission, and Denial-Complaint. These corrections serve to increase diagnostic efficiency and counteract response bias. Following a four-step technique, BR points are added or subtracted to some scale scores (Strack, 1999).

Clinical interpretation. Before the clinician can interpret the personality disorder and clinical syndromes scales, he or she has to establish whether or not the profile is valid. There are 4 scales on the MCMI-III, which assess response characteristics: Validity, Disclosure, Desirability, and Debasement. The validity and Disclosure scales are the only ones, which determine if the test is interpretable, or not.

The Validity Index (Scale V) has 3 improbable statements. If two or more of these statements are endorsed, the test will be deemed invalid. Even if only one of the improbable items has been endorsed, caution should be used with the interpretation of the test.

The Disclosure Index (Scale X) identifies secretive and defensive-low score—or self-revealing and too frank-high score-test takers. This scale is computed from the degree of positive or negative deviation from the midrange of an adjusted composite raw 
score from Scales 1 through 8B. Scores below BR 34 and above 178 make the profile invalid (Strack, 1999).

The Desirability Scale (Scale Y) looks at the degree of which the test taker tries to present himself or herself in an excessively favorable, morally virtuous, or emotionally stable light. Clinicians should look at BR scores above 74. The higher the BR score, the more likely the test taker is denying personal or psychological problems. Score adjustments are made on those scales which are known to be affected by high scores on Scale Y. Therefore, elevations on Scale Y do not necessarily invalidate the profile, however, low scores on Scale Y are not interpreted (Strack, 1999).

Exaggerated presentation of psychological problems and the inclination to report more problems than are objectively present is detected by the Debasement Scale (Scale Z). High scores indicate acute emotional distress, a cry for help, or exaggeration for personal gains. Again, high scores do not invalidate the profile, necessarily, however, scoring adjustments are made to scales affected by high scores on this scale. These Modifying Indices can be interpreted by themselves or together as a group (Strack, 1999).

The publisher of the scale (Pearson) provides automated interpretative reports of the MCMI-III, which can aid the clinician in conceptualizing the patient. Another interpretative manual exists (Choca \& van Denburg, 1997) which takes into account elevations of up to three scales. This manual gives the clinician succinct interpretation hints of the most probable profiles. 
MCMI-III Scales

Clinical Personality Patterns

Scale 1 Schizoid

Scale 2A Avoidant

Scale 2B Depressive

Scale 3 Dependent

Scale 4 Histrionic

Scale 5 Narcissistic

Scale 6A Antisocial

Scale 6B Aggressive (Sadistic)

Scale 7 Compulsive

Scale 8A Passive-Aggressive

Scale 8B Self-Defeating

Severe Personality Pathology

Scale S Schizotypal

Scale C Borderline

Scale P Paranoid

Clinical Syndromes

Scale A Anxiety Disorder

Scale H Somatoform Disorder

Scale N Bipolar: Manic Disorder

Scale D Dysthymic Disorder

Scale B Alcohol Dependence

Scale T Drug Dependence

Scale R Post-Traumatic Stress Disorder

Severe Syndromes

Scale SS Thought Disorder

Scale CC Major Depression

Scale PP Delusional Disorder

Modifying Indices

Scale X Disclosure

Scale Y Desirability

Scale Z Debasement

Validity Index

Scale V Validity 
Internal Consistency and Test-Retest Reliability for the MCMI-III Scales

Scale Number of Items

Internal Consistencya

Reliabilityb

Clinical Personality Patterns

$\begin{array}{lllll}1 & \text { Schizoid } & 16 & .81 & .89 \\ \text { 2A } & \text { Avoidant } & 16 & .89 & .89 \\ \text { 2B } & \text { Depressive } & 15 & .89 & .93 \\ 3 & \text { Dependent } & 16 & .85 & .89 \\ 4 & \text { Histrionic } & 17 & .81 & .91 \\ 5 & \text { Narcissistic } & 24 & .67 & .89 \\ 6 \mathrm{~A} & \text { Antisocial } & 17 & .77 & .93 \\ 6 \mathrm{~B} & \text { Aggressive (Sadistic) } & 20 & .79 & .88 \\ 7 & \text { Compulsive } & 17 & .66 & .92 \\ 8 \mathrm{~A} & \text { Passive-Aggressive (Negativistic) } & 16 & .83 & .89 \\ 8 \mathrm{~B} & \text { Self-Defeating } & 15 & .87 & .91\end{array}$

Severe Personality Pathology

$\begin{array}{lllll}\text { S } & \text { Schizotypal } & 16 & .85 & .87 \\ \mathrm{C} & \text { Borderline } & 16 & .85 & .93 \\ \mathrm{P} & \text { Paranoid } & 17 & .84 & .85\end{array}$

Clinical Syndromes

\begin{tabular}{|c|c|c|c|c|}
\hline A & Anxiety & 14 & .86 & .84 \\
\hline $\mathrm{H}$ & Somatoform & 12 & .86 & .96 \\
\hline $\mathrm{N}$ & Bipolar: Manic & 13 & .71 & .93 \\
\hline $\mathrm{D}$ & Dysthymia & 14 & .88 & .91 \\
\hline B & Alcohol Dependence & 15 & .82 & .92 \\
\hline $\mathrm{T}$ & Drug Dependence & 14 & .83 & .91 \\
\hline $\mathrm{R}$ & Post-Traumatic Stress Disorder & 16 & 89 & .94 \\
\hline
\end{tabular}

Severe Syndromes

$\begin{array}{llll}\text { SS } & \text { Thought Disorder } & 17 & .87\end{array}$

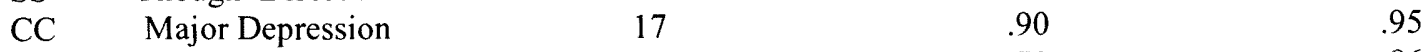

$\begin{array}{llll}\text { PP } & \text { Delusional Disorder } & 13 & .79\end{array}$

Modifying Indices

\begin{tabular}{lllcc}
$\mathrm{X}$ & Disclosure & $\mathrm{N} / \mathrm{A}$ & $\mathrm{N} / \mathrm{A}$ & .94 \\
$\mathrm{Y}$ & Desirability & 21 & .86 & .92 \\
$\mathrm{Z}$ & Debasement & 33 & .95 & .82 \\
\hline
\end{tabular}

aCross-validation sample $(n=398)$.

bTest-retest interval 5-14 days, retest sample $(n=87)$. 
Appendix B 


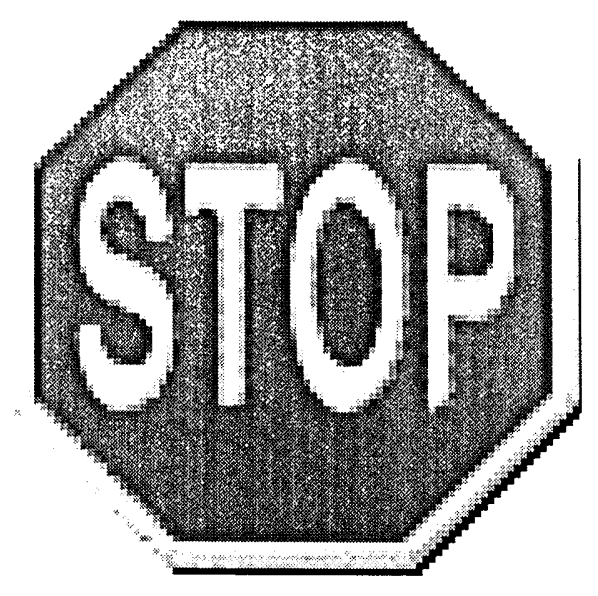

\section{It's Not Personal!}

A workshop research study on how to better understand yourself and your relationship!

This workshop focuses on teaching techniques that improve your ability to:

$\checkmark$ understand yourself.

$\checkmark$ communicate effectively with your partner.

$\checkmark$ soothe yourself during an argument.

ON-GOING WORKSHOPS - TO ENROLL CALL:

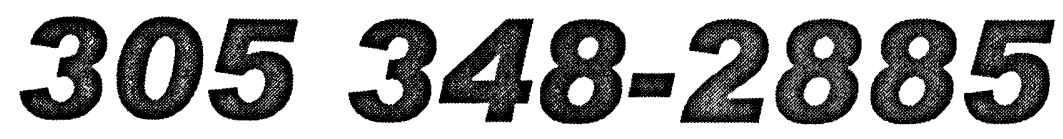

The Youth \& Family Development Lab Florida International University 
Appendix $\mathrm{C}$ 


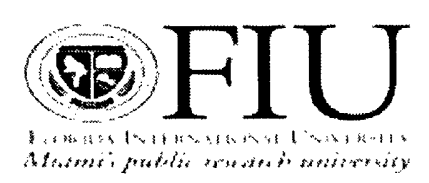

\section{CONSENT TO PARTICIPATE IN A RESEARCH STUDY Title: Assessment Feedback}

You are being asked to be in a research study. The investigator of this study is Andrea Allen, a student at FIU. The study will include about 75 people from the Miami area. Your participation will require 2 hours of your time over 2 weeks. We are looking at people's reactions and responses to psychological testing. At conclusion of this study, you will have an opportunity to participate in a 4 week relationship workshop that will meet for 1 hour each week. The investigator of that study, Michelle Hospital, a student at FIU, will provide you with additional information about this workshop.

Your participation in the assessment feedback study is not contingent on your participation in the workshop. Your participation in the workshop is not contingent on your participation in the assessment feedback study. Your participation in any part of the study is completely voluntary. If you decide to be a part of the study we will tell you what day and time to come to the Youth and Family Development Lab (DM 268). You will be asked to fill out a survey asking for basic personal information. You will also be asked to complete several questionnaires that ask questions about your feelings about yourself and your relationships with others. About 2 weeks after that, you will then be asked to attend an individual session with the investigator to talk about your assessment. After that, you will be asked to again fill out some of the same questionnaires that you completed in the beginning.

We do not expect any harm to you by being in the study. If you get upset or feel discomfort during the workshop, you may ask to take a break. There is no cost or payment to you as a subject. However, your help will give us information about people's reactions to psychological testing.

Your information will be identified by a random number not your name. All of your answers are private and will not be shared with anyone unless required by law. Your data will be compared to the data of the other subjects. We will present the research results as group data. You may ask questions about the study at any time. If you choose not to participate, no one will be upset with you. You may also choose to stop your participation at any time.

If you would like more information about this research after you are done, you can contact Dr. Montgomery or me at 305-348-2885. If you would like to talk with someone about being a 
subject in this study you may contact Dr. Bernard Gerstman, the Chairperson of the FIU Institutional Review Board at 305-348-3115 or 305-348-2494.

This study has been explained to me. All of my questions have been answered to my liking. I am aware of my rights and I agree to be in the study.

Signature of Participant

Printed Name

Date

I have explained the research procedure, subject rights and answered questions asked by the participant. I have offered him/her a copy of this informed consent form.

Signature of Witness

Date

Florida International University

University Park, Miami, Florida 33199 


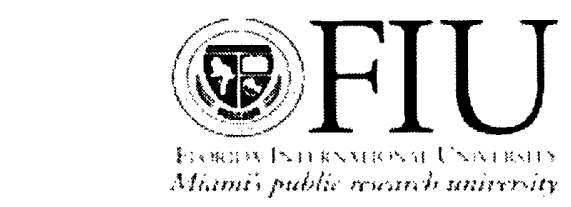

\section{INFORMED CONSENT FOR TAPE RECORDING}

\section{Title of Study: Assessment Feedback}

You have signed an informed consent form as to your participation in the research project "Assessment Feedback." Additionally, you are being asked to authorize FIU to record on audiotape your participation in the research project "Assessment Feedback," and to exhibit such recording(s), in whole or in part, without restriction or limitation, for educational or research purposes which FIU shall deem appropriate.

Your signing of this informed consent for tape recording form is voluntary. Your participation in the research project is not dependent on your signing of this informed consent for tape recording, nor do you have to sign this form to continue your participation in this research project.

By signing this form, you acknowledge that this consent and release is for the duration of the project, and you release Florida International University from any claim that you may have by reason of the making or playing of the recording(s). You understand that the tapes used for the recording(s) will only be labeled with an identification number and not with any names. Should you feel uncomfortable during the taping process, you may ask to have the tape stopped. This will in no way affect your participation in the research project.

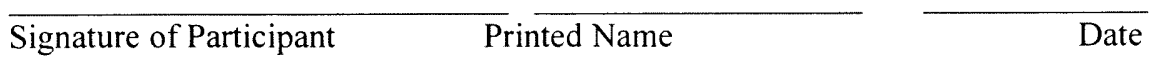

I have explained the procedure and answered questions asked by the participant. I have offered $\mathrm{him} /$ her a copy of this consent form.

Signature of Witness
Florida International University
University Park, Miami, Florida 33199 
Appendix D 


\section{Clinical Personality Patterns}

Scale 1 Schizoid

Scale 2A Avoidant

Scale 2B Depressive

Scale 3 Dependent

Scale 4 Histrionic

Scale 5 Narcissistic

Scale 6A Antisocial

Scale 6B Aggressive (Sadistic)

Scale 7 Compulsive

Scale 8A Passive-Aggressive

Scale 8B Self-Defeating

Severe Personality Pathology

Scale S Schizotypal

Scale C Borderline

Scale P Paranoid $\rightarrow$

$\rightarrow$

$\rightarrow$

$\rightarrow$

$\rightarrow$

$\rightarrow$

$\rightarrow$

$\rightarrow$

$\rightarrow$

$\rightarrow$

$\rightarrow$

Retiring

Hesitating

Depressive

Agreeing

Outgoing

Asserting

Dissenting

Controlling

Conforming

Negativistic

Yielding

No Equivalent

No Equivalent

No Equivalent 
Appendix E 


\section{Verbal Response Mode Categories}

Approval: $\quad$ Provides emotional support, approval, reassurance, or reinforcement. It may imply sympathy or tend to alleviate anxiety by minimizing the client's problems. Examples: "It'll get better." "Don't worry about it."

Information: Supply information in the form of data, facts or resources. Examples: "I looked over your answers last week." "We will meet twice a week."

Closed Question: Used to gather data. It requests a one-or-two-word answer. Examples: "Did you like that?" "How much do you weigh?"

Open Question: Requests clarification or exploration by the client. Does not necessarily ask for a specific answer, but asks about the clients thoughts about the topic. Examples: "How do you feel about that?" "Tell me more about that."

Paraphrase: $\quad$ There can be four types that fall into this categoryrestatements, reflections, nonverbal referents, and summaries. All of these responses essentially paraphrase, mirror or summarize what the client has been communicating. Examples: "You are pleased and satisfied with your performance." "You're saying that your father does not want to support you anymore."

Interpretation: $\quad$ Must GO BEYOND what the client has overtly stated or recognized. Presents a new meaning or gives a reason or insight for behaviors or feelings. Usually helps the client see things in a new way. Examples: "He seems to be saving you from any decision."

Other: Includes statements which are related to the client's problems, such as small talk, or salutations. Examples: "Thank you." "Excuse me." 
RATING FORM OF INTERVIEWER

DATE:

PARTICIPANT \#

NAME OF REVIEWER:

Instructions: Complete this form while listening to the feedback sessions. Do a frequency check for the response modes you hear.

\begin{tabular}{|l|l|l|l|}
\hline $\begin{array}{l}\text { Response } \\
\text { Mode }\end{array}$ & $\begin{array}{l}\text { Frequency } \\
\text { Count }\end{array}$ & Total & Comments \\
\hline Attending & & & \\
\hline $\begin{array}{l}\text { Open } \\
\text { Question }\end{array}$ & & & \\
\hline $\begin{array}{l}\text { Reflection of } \\
\text { Content }\end{array}$ & & & \\
\hline $\begin{array}{l}\text { Reflection of } \\
\text { Feeling }\end{array}$ & & & \\
\hline $\begin{array}{l}\text { Information } \\
\text { Interpretation }\end{array}$ & & & \\
\hline $\begin{array}{l}\text { Other (small } \\
\text { talk or } \\
\text { salutations) }\end{array}$ & & & \\
\hline
\end{tabular}

Notes/Unclassifiable Responses: 
Appendix $\mathrm{F}$ 


\section{Demographic Questionnaire}

1. Gender (circle one): $\quad$ Male $\quad$ Female

2. Age: years

3. Please check all ethnic identifiers you feel describe you:

White, not of Hispanic origin

Black, not of Hispanic origin

Haitian

Jamaican

Cuban

Hispanic/Latino, please specify:

Other Caribbean, please specify:

Asian or Pacific Islander

American Indian

Other, please specify:

4. Were you born in the United States (circle one):

YES NO

If no, where were you born?

5. Was your mother born in the United States (circle one): YES NO If no, where was she born?

6. Was your father born in the United States (circle one): YES NO If no, where was he born?

7. If you were not born in the United States, are you here permanently or temporarily?

8. What was the first language you learned to speak?

9. What other languages do you speak fluently?

10. How would you best describe your yearly income? (If you depend on family members for support, please include their yearly income.) (circle one)

Below $\$ 30,000 \quad \$ 30,000$ to $\$ 50,000 \quad \$ 50,000$ to $\$ 100,000$

more than $\$ 100,000$

11. Where do you live for the majority of the year? (circle one)

On campus with parents house/apartment other (specify) 
12. Do you have any brothers and/or sisters?

YES NO

If yes, please list ages of brothers

If yes, please list ages of sisters

13. How many years of school have you completed?

High School

Freshman year of college

Sophomore year of college

Junior year of college

Senior year of college

14. What is your current dating or marital status? (check all that apply)

Separated

Widowed

Divorced

Not dating

Casually dating

Dating (6 months or longer)

Dating (1 year or longer)

Living with a partner

15. Do you have any children?

If yes, how many?

YES NO

How old were you when you became a mother/father? 


\section{SLCS-R}

Please indicate how much you agree with each of the 16 statements below. Be as honest and as accurate as possible. Do not skip any statements. Respond to the statements in the order they appear. Use the following scale:

\begin{tabular}{lllll}
\multicolumn{1}{c}{1} & 2 & 3 & $\begin{array}{c}4 \\
\text { strongly } \\
\text { disagree }\end{array}$ & 5 \\
agree & & &
\end{tabular}

Indicate your responses by placing a number (1-5) in the space provided before each statement.

1. I I tend to devalue myself.

2.___ I am highly effective at the things I do.

3._I I am comfortable with myself.

4._I I am almost always able to accomplish what I try for.

5. I I am secure in my sense of self-worth.

6. It is sometimes unpleasant for me to think about myself.

7. I have a negative attitude toward myself.

8. At times, I find it difficult to achieve the things that are important to me.

9._I feel great about who I am.

10. I sometimes deal poorly with challenges.

11._I never doubt my personal worth.

12._I I perform very well at many things.

13. I sometimes fail to fulfill my goals.

14._I I am very talented.

15._I I not have enough respect for myself.

16._I wish I were more skillful in my activities. 


\section{P M}

\section{COUNSELOR PER CEPTION M EA S U R E}

Counselors can be described in terms of various characteristics. There are 12 possible counselor characteristics listed on this sheet. For each of these, please mark the number on the scale that reflects the extent to which the examiner you saw showed that characteristic.

Here are two examples:

1. Humorous

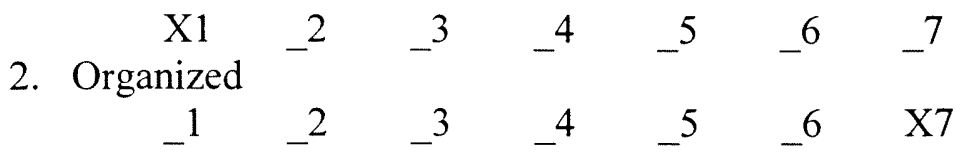

Answers like these would mean that you saw the counselor as being not at all humorous and very well organized.

All the counselor characteristics listed below are positive, but counselors differ a great deal in the characteristics the show. For each of these, please mark the number on the scale that reflects the extent to which the counselor you saw showed that characteristic.

1. Friendly

2. Firm

$$
\underset{\text { Never }}{1} \quad-{ }_{\text {Seldom }}^{2}-{ }^{3} \underset{\text { Sometimes }}{4} \quad \frac{5}{\text { Often }} \quad-{ }_{\text {Always }}{ }^{7}
$$

3. Caring

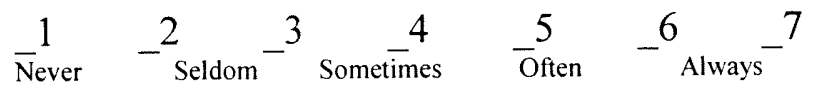

$$
{ }_{\text {Never }}^{1} \quad{ }^{2}{ }_{\text {Seldom }}{ }^{3} \underset{\text { Sometimes }}{4} \quad \stackrel{5}{\text { Often }} \quad-{ }_{\text {Always }}^{6}-7
$$

4. Accepting

$$
\frac{1}{1} \quad{ }_{\text {Never }}^{2}{ }_{\text {Seldom }}{ }^{3} \underset{\text { Sometimes }}{-4} \quad{ }_{\text {Often }}^{5} \quad-6{ }_{\text {Always }}{ }^{7}
$$

5. Straight-forward

6. Expert

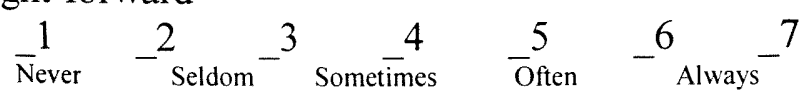

7. Sensitive

$$
\bar{N}_{\text {Never }}^{1} \quad{ }^{2}{ }_{\text {Seldom }}{ }^{3}{ }_{\text {Sometimes }}^{-4} \quad-5 \text { Often }^{-6} \quad{ }_{\text {Always }}^{-7}
$$

$$
\frac{1}{1} \quad{ }_{\text {Never }}^{2}{ }_{\text {Seldom }}-{ }^{3} \underset{\text { Sometimes }}{\stackrel{4}{4}} \quad \bar{O}_{\text {Often }}^{5} \quad-{ }_{\text {Always }}^{6}{ }^{7}
$$




\section{Competent}

9. Knowledgeable

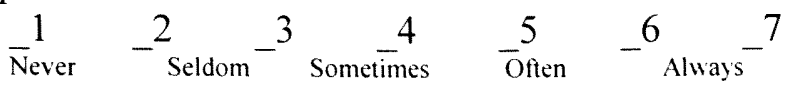

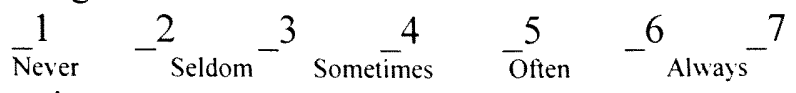

10. Supportive

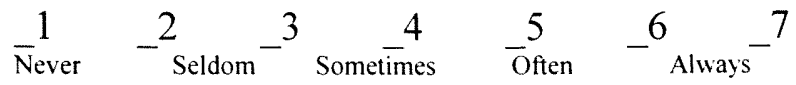

11. Confident

$$
\frac{1}{\text { Never }} \quad-{ }_{\text {Seldom }}^{2}-{ }^{3} \underset{\text { Sometimes }}{4} \quad \frac{5}{\text { Often }} \quad-{ }_{\text {Always }}^{6}{ }^{7}
$$

12. Understanding

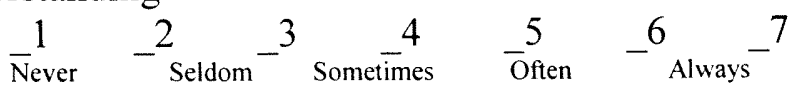




\section{A N D R E A A L L E N}

- Ph.D. candidate, Psychology, Life-Span Developmental Science, Fall 2004

- Advancement to doctoral candidacy in 2003

- State Registered Intern in Mental Health Counseling in 2002; licensure examination: Spring 2005

- M.S., Psychology in 2001

1994-1997 University of South Florida Tampa, FL

- B.A., Psychology in 1997

- Teaches undergraduate psychology classes (Psychotherapy, Theories of Personality, Abnormal Psychology).

2001-present Florida International University

Miami, FL

Therapist, Child and Family Psychosocial Research Center,

Child Anxiety and Phobia Program

- Conducts cognitive-behavioral therapy with clients of the Child Anxiety and Phobia Program

- Conducts diagnostic assessments with families.

1999

Miami-Dade Community College

Miami, FL

Language Teacher

- Taught intensive ESOL classes at local community college.

1997-1998 Mental Health Care, Inc-Baylife Division Tampa, FL Counselor III

- Provided day treatment and therapeutic counseling services to clients of a mental health center. Assumed supervisory functions in absence of 
supervisor.

\section{Counselor II}

- Provided case management and supportive counseling services to clients of a community mental health center.

- Performed client and program related record-keeping functions.

1995

University of South Florida

Tampa, FL

Research. Assistant in the Department of Psychology and Surgery

- Worked as research assistant and trained as histologist in neuropsychological laboratory.

- Responsibilities included processing of tissue and preparation of slides.

American Psychological Association, Student Affiliate

Association for Advancement of Behavior Therapy, Student Member

American Mental Health Counselors Association, Student Member

Allen, A., Montgomery, M., Tubman, J., Frazier, L., \& Escovar, L. (2003). The effects of assessment feedback on rapportbuilding and self-enhancement processes. Journal of Mental Health Counseling, 25, 165-181.

Allen, A., Lissette M. Saavedra, \& Rey, Y. (2003, April) Gender Role Orientation and Self-ratings of Fear among Hispanic American Adolescents. Poster presented at the 2003 biennial meeting of the Society for Research in Child Development.

Allen, A., Frazier, L., Montgomery, M., Tubman, J., \& Escovar, L. (2002, August). Effects of Assessment Feedback on the Rapport Building Process. Poster presented at the annual meeting of the American Psychological Association, Washington, DC. 